\title{
Morphosyntactic Correspondence in Bantu Reduplication *
}

\author{
Larry M. Hyman, Sharon Inkelas \& Galen Sibanda \\ University of California, Berkeley
}

\section{Introduction}

Since the pioneering work of Marantz (1982), Kiparsky (1986), McCarthy \& Prince (1986) and others, the primary goal in the study of partial reduplication has been to construct a theory that insightfully captures the full range of considerations that speakers may invoke in determining how a reduplicant will relate to its base. Given that both phonology and morphology are potentially involved, this has meant two things. First, there has been an attempt to characterize the reduplicant in prosodic terms: the shape of a reduplicant is frequently defined by reference to foot-, syllable- and/or moraic structure. Second, and more recently, the literature has shown an increasing awareness of the role of MORPHOLOGICAL structure in determining the base-reduplicant relationship. Researchers such as Downing (1997 et seq.), Urbanczyk (1996), McCarthy \& Prince (1993, 1995) have shown that, in addition to prosodic constraints, the realization of a reduplicant may be influenced by purely morphological conditions. In Bantu verb stem reduplication, for example, simplex stems may reduplicate differently from polymorphemic ones, and these latter may show further differentiations, depending on whether the affixes are derivational vs. inflectional in nature. Some of these morphological conditions can be quite subtle, and yet, as we shall show, provide crucial evidence for our very conception of how and where (partial) reduplication takes place within a grammar. In short, reduplication provides an ideal testing ground for theories of morphology, phonology, and their interface.

In this paper we provide a detailed description of verb-stem reduplication in Ndebele, a Southern Bantu language of the Nguni group, which also includes Zulu, Xhosa and Swati. We show that the reduplicant in Ndebele is not only conditioned by phonological and morphological factors, as in other Bantu languages, but that these factors are "abstract" in nature: Despite surface appearances to the contrary, the reduplicant of an Ndebele verb stem must be analyzed as a verb stem itself (cf. Downing 1997a et seq.). Its surface form is obtained not by surface correspondence to the base output, but rather by direct spell-out of its own (identical) morphosyntactic structure, which, in turn, is a direct copy from the base. As schematized in the (typically) prefixal reduplication in (1),

Morphosyntactic Representation (base)
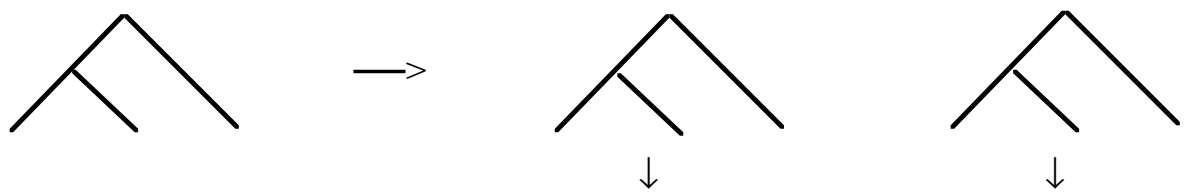

[Surface Reduplicant] + [Surface Base $]$

the input is a left-branching morphosyntactic structure, where the deepest embedded morpheme is the root, e.g. a verb root in our study. The surface outputs to the right of the arrow are obtained in the following way. First, we copy this morphosyntatic representation as a reduplicant to the left of the

\footnotetext{
*Earlier versions of this paper were presented on April 25, 1998 at the Trilateral Phonology Weekend (TREND) meeting in Berkeley and on October 13, 1998 at the CNRS laboratoire LACITO in Paris. We are grateful for the responses received on these occasions as well as from Laura Downing, for comments offered to us in several very helpful discussions. Research on the Ndebele lexicon, conducted in the context of the Comparative Bantu On-Line Dictonary project, has been supported in part by a National Science Foundation grant \#SBR96-16330.
} 
input base. We then spell out both structures independently. What we have identified as the surface base is derived by the normal rules of word formation, constrained by (sometimes conflicting) considerations such as compositionality, morphotactic restrictions etc. (Guthrie 1962, Hyman 1993, Hyman \& Mchombo 1992). The surface reduplicant is also subject to these general considerations, as well as those imposed specifically on the reduplicant. The reduplicant may thus be subject to prosodic as well as morphological constraints. In Ndebele, for instance, the reduplicant is limited to two syllables and inflectional suffixes may not appear within it.

Our conception of verb stem reduplication in Ndebele in (1) differs from most other conceptions in two ways:

First, we make explicit that reduplication is a MORPHOLOGICAL process. While noone would contest this conclusion, research on partial reduplication has mostly been conducted by phonologists who, most recently, emphasize surface base/reduplicant correspondence, and hence view morphology in terms of surface morphs rather than morphosyntactic structure. With Inkelas \& Zoll (1999) we do not assume a direct phonological correspondence between the reduplicant and the base.

Second, we take the position that partial reduplication is derived from total reduplication (cf. Steriade 1988). The conception in (1), however, goes beyond phonological "full copy" theories such as Steriade (1988), in explicitly treating reduplication as the total copy of the abstract morphosyntactic structure of the base. If there are no special phonological or morphological conditions on the reduplicant beyond those characterizing the base, we in fact derive total reduplication on the surfacean apparent compounding of a base with itself. If there ARE special conditions, we obtain partial reduplication. We thus agree, in part, with Eulenberg (1971:73) who states that "cases of so-called partial reduplication are simply phonological reductions, sometimes drastic, from cases of full reduplications." As will be seen below, we propose to revise Eulenberg's statement to read "phonological OR MORPHOLOGICAL reductions."

In many, if not most cases of partial reduplication, there will be no difference between our morphosyntactic approach vs. the "morph" approaches that have characterized the prosodic analysis of reduplication since Marantz (1982) and McCarthy \& Prince (1986). This is because in most situations the properties (e.g. linear order) of surface morphs (specifically, affixes) generally mirrors the underlying morphosyntactic representation. In Bantu, however, there are widespread instances where this is not the case. As we shall see in $\S 5$, where there is a mismatch between the surface order of suffixes vs. the underlying morphosyntactic representation, it is the latter that determines what can appear in the reduplicant.

The paper is organized as follows. In $\S 2$ we provide a basic overview of verb stem reduplication in Ndebele. In subsequent sections we treat complications arising in the reduplication of stems containing subminimal or "consonantal" verb roots (§3), fusion or "imbrication" of perfective -ile (§4), and the passive suffix $-w$ - (§5). We then conclude by considering synchronic and diachronic implications of our findings.

\section{Basic overview}

We begin by considering the basic properties of verb-stem reduplication in Ndebele. In (1) we first consider verb stems that consist of a "long" root $(\geq C V C)$ and the default inflectional final vowel suffix $-a$. The meaning of such reduplications generally is to do the action in little bits, here and there, perhaps not very well. The forms are given in their minimal citation form, i.e. minus inflectional prefixes (and with underlying high tone marked on the first vowel of verb roots). With one major exception which we shall examine in $\S 3$, prefixes are irrelevant to stem reduplication. We will adhere 
to the notational convention of separating reduplicant and base with the "+" symbol, reserving "-" for internal morpheme breaks: ${ }^{1}$

(2) Reduplicant (RED) is exactly two syllables

\section{Plain verb stem}

a. lim-a thum-a $\quad(\mathrm{H})$

b. nambith-a (H) thembuz-a $(\mathrm{H} / \mathrm{L})$

\section{Reduplicated verb stem}

$\begin{array}{ll}\text { lim-a+lim-a } & \text { 'cultivate' } \\ \text { thum-a+thum-a } & \text { 'send' } \\ \text { nambi+nambith-a } & \text { 'taste' } \\ \text { thembu+thembuz-a } & \text { 'go from wife to wife' }\end{array}$

The pattern in (2a), in which the verb root $=C V C$, shows a total reduplication of the verb stem. In $(2 b)$, however, where the verb root $>\mathrm{CVC}$, we see that the reduplicant is limited to two syllables, i.e. to a bisyllabic foot. In both sets of examples the reduplicant is identical to the first two syllables of the base verb stem.

However, when we turn to cases of productively suffixed roots in (3), we find that something more subtle is going on. In these examples, where -el-is the applicative suffix and -is-is the causative suffix, we see that there are TWO possible shapes of the reduplicant: it can either be identical to the first two syllables of the base, hence lim-e and lim-i, respectively, or it can end in [a], thus lim-a.

(3) Plain verb stem Reduplicated verb stem
a. lim-el-a
lim-e+lim-el-a
'cultivate for $/ \mathrm{at}^{\prime}$
(applicative -el-)
b. lim-is-a
lim-i+lim-is-a
'make cultivate'
(causative -is-)

In order to account for this variation, consider the traditional view of the internal structure of the Bantu verb stem in (4).

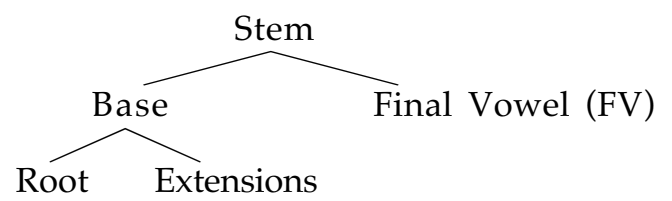

(cf. Meeussen 1967)

As seen, a verb stem consists of a base and an obligatory final vowel (FV) morpheme, which is [a] in most verb forms. Within what Bantuists refer to as the "base", a root may be "extended" by derivational suffixes (or extensions). Among the Ndebele extensions that we consider in this study are applicative $-e l-$, causative $-i s-$, and passive $-w-$.

The second variants in (3a) and (3b) show that the extension vowel may optionally not appear in the reduplicant, in which case the reduplicant is pronounced with a final [a]. As seen in (5a), this second variant ending in [a] is NOT available if the verb root is polysyllabic:

(5) a. nambith-a (H) *namb-a+nambith-a 'taste'

thembuz-a $(\mathrm{H} / \mathrm{L})$ *themb-a+thembuz-a 'go from wife to wife'

${ }^{1}$ Verb tone is indicated throughout by $(\mathrm{H})$ following verb stems with High tone roots and $(\mathrm{H} / \mathrm{L})$ following verbs in which the root can take both High and Low tone. Unmarked forms have Low-toned roots. High tone on consonantal roots is realized only in the presence of extension suffixes. 


$\begin{array}{clcc}\text { b. casuk-a } & \begin{array}{c}\text { casu+casuk-a } \\ \text { *cas-a+casuk-a }\end{array} & \text { 'become nauseated' } & \text { / cas-uk-a/ } \\ \text { casul-a } & \begin{array}{l}\text { casu+casul-a } \\ \text { *cas-a+casul-a }\end{array} & \text { 'nauseate' (tr.) } & \text { / cas-ul-a/ }\end{array}$

A final [a] is also not possible in (5b), where the input verbs carry the non-productive reversive suffixes $-u k-$ and $-u l-.^{2}$

Finally, to complete this introduction to the basics, note in (6) that the reduplicant cannot include inflectional material occurring in the so-called "final vowel" slot:

(6) The reduplicant cannot contain inflectional material of the base, e.g. the finals $-e,-i$ or $-i l e$
a. lim-e $\rightarrow$ lim-a+lim-e (subjunctive -e)
*lim-e+lim-e
b. $\quad$ lim-i $\rightarrow$ lim-a+lim-i (negative $-\mathrm{i}$ )

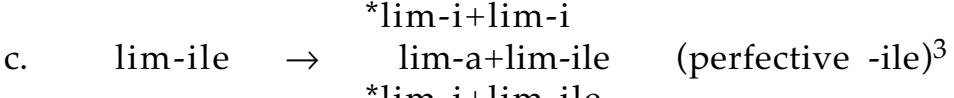

These examples are significant for two reasons. First, they show that inflectional suffixes are outside the scope of reduplication. Second, they show that the source of reduplicant-final [a] is not necessarily the base, as one might have presumed from [a]-final reduplicants in (3). The data in (6) make it clear that there is an independent source for reduplicant-final [a].

In all of the above regards, Ndebele verb-stem reduplication is equivalent to that in Swati, for which Downing (1997a et seq.) proposes the Bantu verb stem structure in (7).

(7) Bantu verb stem according to Downing; cf. Meyers (1987)
a. I-stem = Inflectional stem
c. $\quad$ Root $=$ minimal D-stem
b. $\quad$ D-stem $=$ Derivational stem
d. $\mathrm{X}+\mathrm{a}=$ "canonical stem" (CS)

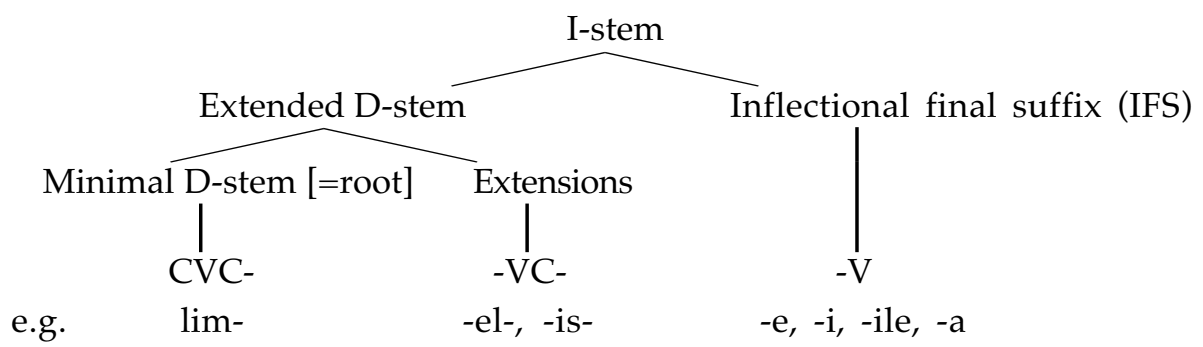

\section{Must copy May copy $\quad$ Cannot copy}

As seen, the full verb stem is referred to as an inflected stem (or I-stem), which in turn has two parts: (i) a D-stem, which may be potentially extended by derivational suffixes, and (ii) an inflectional final suffix. The root is identified as the minimal D-stem. In (7) this structure is exemplified with the root

${ }^{2}$ In some Bantu languages there are independently occurring -CVC- roots whose actions may be "reversed" by adding these suffixes, e.g. Bemba -kak- 'tie', -kak-uk- 'become untied', -kak-ul- 'untie'. Such examples are lacking in Ndebele, where -uk- and -ul- only occur on "bound roots". See also Schadeberg (1982), who refers to -uk- and -ul- as "separative" suffixes.

${ }^{3}$ Technically, -ile can be demonstrated to consist of two suffixes, -il-e, since the passive -w- appears between them, e.g. si-thúny-i-w-e 'it was sent' (cf. corresponding active stem: / thum-il-e/). 
lim- 'cultivate', the applicative and causative extensions -el- and -is-, and the inflectional final vowels $-e,-i$, -ile and $-a$. Downing refers to any verb stem that ends in the final vowel $-a$ as a "canonical stem".

To summarize the facts we have seen thus far, and as indicated in the last line of (7), the root -limmust be copied into the reduplicant, the vowels [e] and [i] of applicative -el- and causative may optionally copy, and the [e] and [i] of the inflectional suffixes $-e,-i$ and -ile may not copy. If the structure of the input "base" stem is as in (7), the analytical challenges before us are the following:

First, by what means do we ensure that only derivational suffixes, not inflectional ones, are available to reduplicate?

Second, by what means do we ensure that the CVC-a reduplication pattern is permitted with CVC-VC-V stems but not with CVCVC-V stems?

That is, why are the forms in (8a) acceptable, while those in (8b) are not?

(8) Only productive derivational suffixes are replaceable with FV [a] in CVC-a reduplication

a. $\underline{\text { lim-a }}+$ lim-el-a, $\underline{\text { lim-a }}+$ lim-is-a

b. * namb-a +nambith-a, ${ }^{*}$ themb-a + thembuza

Downing's $(1997 a, b)$ position in (9a) is that in the case of CVC-a reduplicants, the CVC-string must correspond to an independently existing minimal D-stem, which lim- in (8a) clearly is.

(9) a. Downing (1997 et seq): CVC- of CVC-a RED must be a corresponding minimal D-stem ${ }^{4}$

b. Steriade (1997): CVCa RED must be a corresponding word (cf. imperative lima!)

On this account, the CVC-a reduplicants in (8b) are disallowed because namb-and themb- do not exist as roots, and therefore the requisite minimal D-stems, *namb-a and *themb-a, do not independently exist. Steriade (1997) slightly amends the story in (9b) to refer to existing vs. non-existing words, noting that $\lim -a$ (8a) exists as a corresponding imperative verb, while *namb-a and *themb-a (8b) do not.

In this paper we do not speak of a reduplicant as corresponding to a stem. Rather, it IS a stem, which is in morphosyntactic featural agreement with the following, "normal" stem that it appears to reduplicate. As seen in (10),

Reduplication as stem juxtaposition:

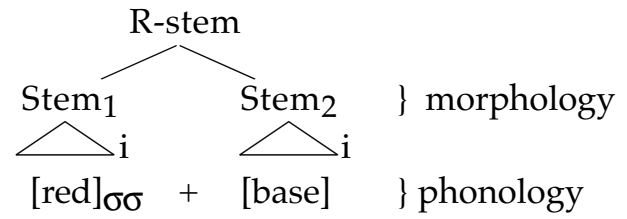

reduplication is stem juxtaposition, where Stem $_{1}$, the reduplicant, is subject to a bisyllabic size constraint, and, as indicated by the subscript on its morphosyntactic structure, is in perfect featural agreement with Stem2, the base.

At this point we note that there are two inviolable morphological properties of base verb stems:

4 Cf. Peng's (1991) recognition of the shape CVC as a "canonical root", which need not correspond to an actually occurring root in truncated reduplication in Kikuyu (cf. (86) below). 
(11) Inviolable morphological properties of base verb stems

a. verb stems must contain a verb root

b. verb stems must be morphologically complex

The first property is self-evident: one cannot have a stem of any sort that does not in turn consist of a root. The second property is what interests us here: Verb stems in Ndebele (and in most Bantu languages) must be bipartite, i.e. suffixed. That is, there must not be a right-alignment of the verb root with the verb stem:

$$
{ }^{*}\left[[\text { verb }]_{\text {root }}\right]_{\text {stem }}
$$

While it has been hypothesized that pre-Proto-Bantu may not have required a suffixal vowel on all verb roots (Grégoire 1979), verb stems in Ndebele must end in one of the inflectional endings-the most generally distributed one being $-a .^{5}$

In this study we follow the tradition of identifying $-e,-i$ and -ile as inflectional endings, i.e. as Downing's IFSs. We shall depart from previous scholarship, however, in treating $-a$ not as an inflectional ending, but rather as the default stem suffix in Bantu in general:

The Bantu default stem suffix -a

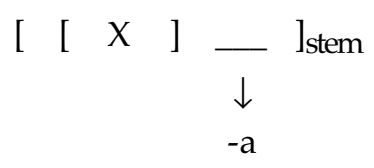

As indicated in (13), - $a$ may be invoked, typically in final position, to "fill out" ANY kind of stem: Dstem, I-stem, R-stem. The suffix - $a$ differs from other verb and noun endings in having no corresponding morphosyntactic feature(s): Unlike $-e,-i$ and $-i l e$, it does not directly realize tense/aspect, mood or polarity distinctions on verbs. While these morphs spell out feature complexes that include [+subjunctive], [+negative] or [+perfective], $-a$ appears only in their absence-i.e. as a DEFAULT. We shall henceforth refer to $-a$ as the FV, reserving IFS for the other final suffixes. ${ }^{6}$

With this interpretation of $-a$ established, we can now explain why $-a$ can appear in the reduplicant, while IFSs may not: These latter may occur only in an I-stem, while the reduplicant is a Dstem in Ndebele. Since $-a$ is devoid of inflectional features, it may appear as a default ending on any

It should thus be noted that much (but not all) of what we shall have to say about Ndebele is characteristic of Bantu in general. In Ndebele and in most Bantu languages, a requirement that all syllables end in a vowel is also necessary, since *lim-el- 'cultivate for' branches, but is not well-formed; it must be augmented to lim-el-a. This phonological requirement is, however, not sufficient to explain all of the environments of -a in Bantu since there were a limited number of -CV- and -CVCV- verb roots in Proto-Bantu (e.g. *-dí- 'eat', *-jg- 'hear') which even today cannot be realized without -a in the relevant daughter languages. Similarly, verbs whose extended D-stems end in causative *-- or passive ${ }^{*}$-u- also require -a. (Ndebele is irrelevant here, since it has restructured V-final verb roots and extensions to be consonant-final, e.g. -dl- 'eat', -zw- 'hear', passive -w-). Note, finally, that some Bantu languages may have a very small number of "defective" verbs that exceptionally occur without an inflectional ending in part of their paradigm, e.g. *-tí 'say', *-jji 'know'.

${ }^{6}$ We shall show in $\S 6$ that default -a may be invoked either in verb or noun morphology, and may appear in either a derivational or inflectional context. 
kind of stem, e.g. the reduplicant D-stem, which, by definition, will not carry an IFS. Our proposal in (14) is that the R-stem is a daughter of Downing's I-stem and sister to her IFS:7

(14) The R-stem is a daughter of the I-stem and sister to inflectional material.

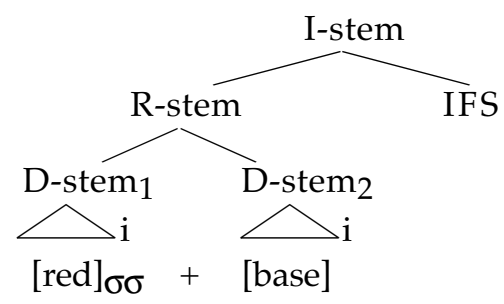

Each of the stems under the R-stem in (14) is a D-stem, although the reduplicant is limited to two syllables. We assume, as is the case in D-stems, that $-a$ is always available to reduplicants as well. As seen in (15), this gives rise to the variation seen in reduplication of D-stems that have extension suffixes. We assume, for sake of argument, that FV is present even in (15a), where (due to disyllabic size constraints) it is not parsed:

(15) Reduplicant D-stem of base -lim-is-a 'cause to cultivate for'

a.

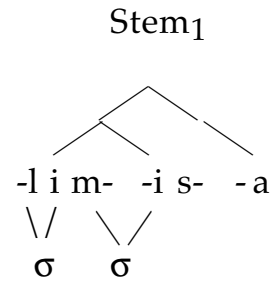

b.

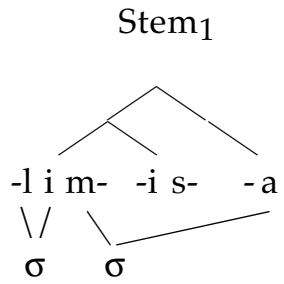

In (15a), the [i] of -lim-i comes from the causative suffix -is-, while in (15b) it comes from the FV $-a$.

Now note with respect to the articulated structure of the reduplicated verb stem in (14) above that both D-stem 2 and the I-stem should have to branch. In case D-stem 2 is simplex, e.g. -lim-, it would appear to need the FV - $a$. However, this morpheme vies for the same "slot" as the IFSs -e, -i and -ile. Therefore, since $-a$ is featureless, the higher ranked requirement that the IFS be spelled out takes precedence and, in the subjunctive, we get [ [ lim-] -e], rather than [ [lim-a]]. ${ }^{8}$

The fully articulated structure of reduplicated verb stems is seen in (16).

\footnotetext{
${ }^{7}$ We do not treat tone in this paper. However, it is known that tone is not transferred in verb stem reduplication in Ndebele or in Bantu in general-the only known exception being Chichewa (Mtenje 1988, Myers \& Carleton 1996, Hyman \& Mtenje 1999). Where one can tell, the tonal opposition (H/Ø) on verb roots is realized only in D-stem 1 , i.e. the reduplicant. Suffixal $\mathrm{H}$ tones presumably come in at the I-stem level. It may thus be necessary to restrict $\mathrm{H}$ tone from being (independently) realized in D-stem 2 . ${ }^{8}$ This analysis appears also to predict that NON-REDUPLICANT D-stems can also contain the FV $-a$, which is standardly analyzed as a daughter of the I-stem. Under our analysis, FV -a is available to Dstems, but is in competition with the IFSs under I-stem (cf. (16) below). In a context where an IFS is required, the -a option will not be taken.
} 
Articulated structure of reduplicated verb stem

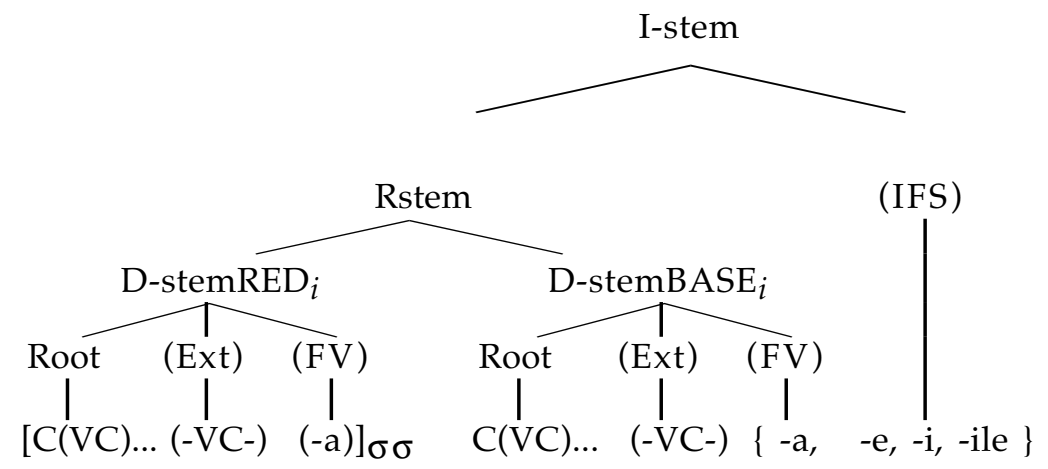

The crucial point in (16) is the disassociation of the FV morpheme - $a$ from the IFS category to which all previous studies have assigned it. As seen, the FV $-a$ is considered to belong to the D-stem, while the inflectional endings $-e,-i$ and -ile, which mark certain subjunctives, negatives, and perfectives, are a property of the I-stem. Since it is a featurally empty morph, the FV - $a$ is able to occur in D-stemRED without disrupting the required morphosyntactic featural agreement between D-stemRED and DstemBASE.

Assuming that the morphological makeup of the reduplicant is as given above, we now turn to its phonological requirements, also indicated in (16). We assume a set of statements roughly like the following, which are phrased for convenience in the terminology of Optimality Theory (Prince \& Smolensky 1993). They are part of the cophonology (phonological "level"; see e.g. Inkelas, Orgun \& Zoll 1997) of Stem 1 in the reduplication construction. They ensure that the reduplicant is of the proper size and determine which elements of the morphological material under the reduplicative D-stem will actually instantiate the bisyllabic reduplicant.

D-stemRED cophonology:

$[\sigma \sigma] \quad: \quad$ The reduplicant is bisyllabic $(=\text { a minimal prosodic word })^{9}$

MAX(Root) : The reduplicant should parse the root (cf. e.g. McCarthy \& Prince 1993, Urbanczyk 1995, Futagi 1997)

$\operatorname{MAX}(E x t) \quad: \quad$ The reduplicant should parse extension suffixes (if any)

$\operatorname{MAX}(\mathrm{FV}) \quad$ : The reduplicant should be faithful to FV $-a$ (if any)

The first constraint requires the reduplicant to assume the exact shape of the minimal prosodic word in Ndebele: one foot consisting of two syllables. This is imperative, and causes the truncation we have observed above. (Later we will see cases where this same constraint causes AUGMENTATION.) The second through fourth constraints are violable, with MAX(Root) ranked above the other two. The last two statements in (17) thus come into play when the root does not exhaust the bisyllabic reduplicant (i.e. when the root is smaller than CVCV, e.g. the CVC root lim-). As we have seen, there are two options for realizing the bisyllabic reduplicant in such cases: use material from extension suffixes, if any (as is done in e.g. lim-e+lim-el-a), or use the FV morph, -a (e.g. lim-a+lim-el-a). The equal viability of these two options can be expressed in OT by freely ranking the corresponding constraints (as proposed by Anttila 1994 and Ito \& Mester 1997, among others).

The rankings of the constraints in (17) are given in (18).

${ }^{9}$ We shall see in $\S 3$ that even in the absence of reduplication, the entire verb form is also subject to bisyllabic minimality. 


$$
[\sigma \sigma]>>\operatorname{MAX}(\operatorname{Root})>>\operatorname{MAX}(\operatorname{Ext}), \operatorname{Max}(\mathrm{FV})
$$

The tableaux in (19) and (20) show how these constraints correctly predict the CVCV- and CVCareduplicants of extended CVC roots. (Note our assumption that the filler morph [a] is present in the input. ${ }^{10}$ )

(19) Derivation of reduplicant in lim-e+lim-el-a:

\begin{tabular}{|c|}
\hline $\operatorname{MAX}(\mathrm{FV})$ \\
\hline * \\
\hline \\
\hline
\end{tabular}

(20) Derivation of reduplicant in lim-a+lim-el-a:

\begin{tabular}{rl||c|c|c|c|}
\hline & {$[\sigma \sigma]$} & $\operatorname{MAX}(\operatorname{Root})$ & $\operatorname{Max}(\mathrm{FV})$ & $\operatorname{MAX}(\mathrm{Ext})$ \\
\hline \hline
\end{tabular}

In neither tableau is there a violation of $[\sigma \sigma]$ or $\operatorname{Max}($ Root), since the reduplicants are both bisyllabic and incorporate the entire verb root lim-. In (19), MAX(Ext) is ranked higher than Max(FV). The winning candidate is thus (19a), lim-e+limela, since the reduplicant in (19b), lim-a, could have parsed the [e] of the stem lim-el-a, but didn't. In (20), the constraint Max(FV) is ranked higher than $\operatorname{MAX}(\mathrm{Ext})$. In this case the winning candidate is (20b), lim-a+lim-el-a, since (20a), lim-e+lim-el-a, violates the now higher ranked constraint $\operatorname{Max}(\mathrm{FV})$.

We thus see how the free ranking of the two lowest constraints produces the two reduplicant possibilities. Now compare these results with the corresponding tableaux in (21) and (22), where the input nambith-a has a bisyllabic root:

(21) Derivation of reduplicant in nambi+nambitha:

\begin{tabular}{r||c|c|c|c|}
\hline nambith-a & {$[\sigma \sigma]$} & MAX(Root) & MAX(Ext) & MAX(FV) \\
\cline { 2 - 6 } \\
b.
\end{tabular}

(22) Derivation of reduplicant in nambi+nambitha:

\begin{tabular}{|c|}
\hline MAX (Ext) \\
\hline \\
\hline \\
\hline
\end{tabular}

As seen, *namb-a+nambith-a is ruled out in both (21b) and (22b), because it violates the relatively high ranked MAX (Root) constraint, i.e. the [i] of the root nambith- could have been parsed, but wasn't.

To summarize, we analyze the reduplicant as a D-stem which is constrained in two ways: (a) it is bisyllabic and (b) it must match the base D-stem morphosyntactically. Our analysis resembles those of Downing (1997a et seq.) and Steriade (1997) in relating the reduplicant to an existing morphological constituent: Like Downing, we take the D-stem to be the relevant level. These studies differ from ours, however, in relying on output-output correspondence to relate the reduplicant and base. Thus, in order to

10 Completeness would require us to consider, in addition, reduplicants lacking the FV -a. This would force us to use the additional notational complication of tableaux des tableaux (Itô, Mester \& Padgett 1995) for dealing with allomorphy. We leave this to the reader. 
get the FV - $a$ in the reduplicant, it is necessary that the preceding -CVC- be an existing verb root in the language. In the following sections we shall see that this condition is neither necessary nor sufficient to predict the full range of facts in Ndebele reduplication. We thus consider, in turn, subminimal (§3), imbricated (§4), and passivized (§5) verb forms. In each case we shall observe the overriding importance of reference to roots vs. reference to other elements. The unmistakeable generalization will be that as long as the root is fully parsed, one has great freedom in how the two syllables of the reduplicant is filled out in Ndebele.

\section{Subminimal roots}

Up until now we have been considering cases in which the reduplicant must be phonologically truncated in order to achieve the bisyllabic size condition. In this section we consider the reduplication of verb stems that contain phonologically subminimal verb roots such as those in (23a), in which entirely different behavior is observed.

a. "consonantal roots"

$$
\begin{array}{llll}
\text {-dl- } & (\mathrm{H}) & \text { 'eat' } & \text {-lw- }(\mathrm{H} / \mathrm{L}) \\
-\mathrm{m}- & (\mathrm{H}) & \text { 'fight' }
\end{array}
$$

b. monosyllabic stems
-dl-a (H) 'eat'
$-\mathrm{m}-\mathrm{a}(\mathrm{H})$ 'stand'

$$
\begin{array}{lll}
-l w-a & (H / L) & \text { 'fight' } \\
-z-a & (H / L) & \text { 'come' }
\end{array}
$$

As seen in (23b), when these so-called consonantal roots are followed by the FV - $a$, the resulting stems are monosyllabic. Normally these stems would occur with prefixes.

Compare, however, the imperative forms in (24). The imperative is the only context in which a stem can occur WITHOUTprefixes:

(24) Imperative verbs (singular, affirmative)
a. lim-a 'cultivate!'
thum-a $(\mathrm{H})$ 'send!'
$\begin{array}{ll}\text { bamb-a } & \text { 'catch!' } \\ \text { hlamb-a } & \text { 'swim!' }\end{array}$
b. nambith-a (H) 'taste!' thembuz-a (H/L) 'go from wife to wife!'
bhavum-a 'growl!'
thembis-a $(\mathrm{H})$ 'promise!'
c. yi-dl-a (H) 'eat!' (*dl-a)
yi-m-a (H) 'stand!' (*m-a)
yi-lw-a (H/L) 'fight!' (*1w-a)
yi-z-a $\quad(\mathrm{H} / \mathrm{L}) \quad$ 'come!' $\quad\left({ }^{*} \mathrm{z}-\mathrm{a}\right)$

The examples in (24a) and (24b) show that the unprefixed verb stem is used in the imperative (singular, affirmative), if the verb stem is at least two syllables long. In (24c), however, we see that a monosyllabic stem cannot occur in its bare form in the imperative, but rather acquires an augmentative syllable yi-, known as a "stabilizer" in the Bantu literature, which we analyze as a semantically empty "filler" morph, much like the FV - $a$.

The motivation for augmentation with yi- in (24c) is clear: As in many other Bantu languages (Myers 1987, Kanerva 1989, Mutaka \& Hyman 1990, Downing, in press), Ndebele words are subject to the bisyllabic minimality condition in (25).

$$
\text { Minimal Prosodic word }(\omega)=[\sigma \sigma]_{\text {foot }}
$$

Verbs are required to meet the minimal prosodic word condition in (25) and must thus be augmented by the empty morph yi- where subminimality would otherwise result. This situation arises only with monosyllabic stems in the imperative, where there is no prefix to supply the required second syllable. 
This minimality condition also helps us make sense of the similar size condition on reduplicants: Reduplicants must be minimal prosodic words as well. Reduplicated verbs thus display the nested prosodic word structure depicted in (26).

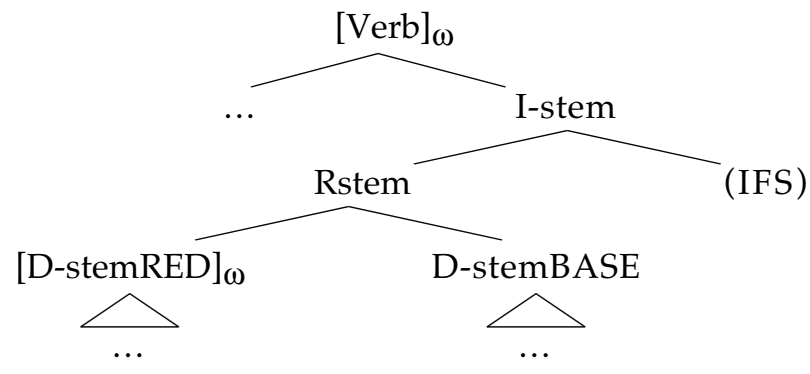

That is, the prosodic structure of a reduplicated verb is: [ Prefixes [ RED ] $]_{\omega}$ BASE+IFS ] $\omega_{\omega}$.

\subsection{Subminimality and augmentative $-y i$}

With this established, we now turn to the question of how monosyllabic verb stems are reduplicated. (27) shows that the augmentative [yi] makes its appearance here as well, this time as a suffix. As shown in square brackets in (27), -yi augments the otherwise subminimal reduplicants of such stems:

Reduplication of monosyllabic stems in the imperative

$$
\begin{aligned}
& \text { [dl-a-yi] +dl-a (H) 'eat!' } \\
& \text { [m-a-yi] +m-a (L) 'stand!' } \\
& \text { [lw-a-yi] +lw-a (H/L) 'fight!' } \\
& \text { [z-a-yi] +z-a (H/L) 'come!' }
\end{aligned}
$$

As seen, -yi appears between the two occurrences of the monosyllabic stem. The (bracketed) reduplicant is subject to the two-syllable requirement, to whose satisfaction the suffixal $-y i$ is a crucial contributor.

The absence of a corresponding -yi in D-stemBASE is no mystery on this account, as D-stemBASE constituents are never subject to the minimality condition which motivates the presence of [yi] in the first place. We know that D-stemRED is required to be exactly bisyllabic. As was seen in (26), the verb as a whole is also required to be minimally bisyllabic, but in the above examples, the whole verb would be bisyllabic anyway even without [yi]. It is, thus, only the reduplicant which would othewise be subminimal.

The data in (28), which contain the infinitive prefix uku-, confirm that the minimality condition is imposed on the reduplicant and on the whole verb but not on ordinary verb stems. Here, the existence of a prefix blocks [yi] augementation in the unreduplicated forms, as the verb as a whole is at least bisyllabic. The fact that the verb stem is monosyllabic is of no relevance. When reduplication is present, however, [yi] augmentation does occur. It is required to supplement the otherwise subminimal reduplicant. In (28), constituents subject to prosodic minimality are show in brackets:

(28) Prefixation has no effect on [yi] augmentation:

Verb with unreduplicated stem Verb with reduplicated stem

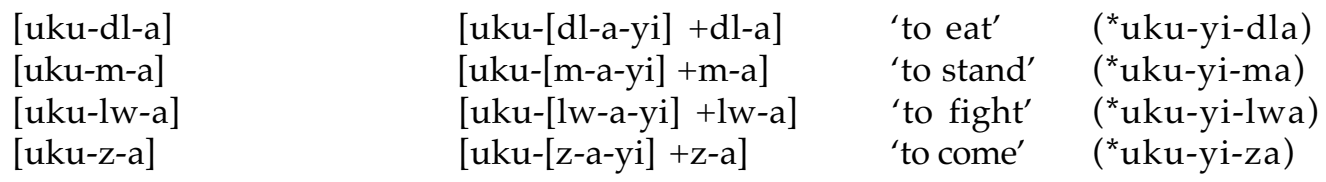


The greatest relevance of consonantal roots for our analysis comes from their behavior under suffixation. D-stems consisting of consonantal roots with extension suffixes show a dazzling variety of reduplication possibilities, as illustrated below:

(29) Variable realization of stems with C- roots (e.g. dl- 'eat'), cited with uku- infinitive prefix.
a. uku-dl-a (H) 'to eat'
uku-[dl-a-yi]+dl-a
b. uku-dl-el-a 'to eat for $/ \mathrm{at}^{\prime}$
uku-[dl-el-a]+dl-el-a
(cf. [lim-e]+lim-el-a)
uku-[dl-a-yi]+dl-el-a
(cf. [lim-a]+lim-el-a)
uku-[dl-e-yi]+dl-el-a
c. uku-dl-is-a 'to feed'
(cf. $[$ lim-i]+lim-is-a)
uku-[dl-is-a]+dl-is-a
(cf. [lim-a]+lim-is-a)
uku-[dl-a-yi]+dl-is-a
uku-[dl-i-yi]+dl-is-a

Again, reduplicants are bracketed. In (29a), a form with no extension suffixes, the input to the reduplicant cophonology consists of the consonantal verb root $d l-$, plus freely available empty morphs $-y i$ and FV $-a$. As seen, there is only one possible outcome, which is to supplement the consonantal root with both empty morphs, yielding a reduplicant of the shape [dl-a-yi].

In (29b) and (29c), in which the base contains a -VC- extension suffix, the same reduplication pattern seen in (29a) is still possible: in the reduplicant, $-y i$ supplements the root and final vowel, yielding in both cases [dl-a-yi]. But in addition, two further reduplication possibilities emerge. One possibility is to exhaustively parse the extension suffix, yielding, in (29b), [dl-el-a], and in (29c), [dlis-a]. The other possibility is to take the vowel from the extension suffix and use -yi to supply the remaining syllable, thus [dl-e-yi] and [dl-i-yi].

In summary, the use of $-y i$ is on a par with the use of the FV $-a$ and material from extension suffixes. Any of these options (singly, or in combination) may be used to supplement a consonantal root and bring a reduplicant to the bisyllabic goal.

(30) Freely rankable options (beyond root parsing) for fleshing out bisyllabic reduplicant:
a. $-y i$
b. - a
c. Material from extension suffixes

Our existing analysis needs to be supplemented with a constraint which makes reference to -yi. Our intuition is that $-y i$ is a morphosyntactically empty morph which can fill an optional position in DstemRED just like the FV morph $-a:^{11}$

D-stemRED

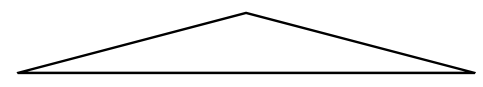

$\operatorname{Root}(\text { Ext })^{*}(-a) \quad(-y i)$

\footnotetext{
${ }^{11}$ We assume that -yi is disallowed in regular D-stems because it serves no function and thus gratituitously violates *STRUC (the general ban on structure of all kinds). Below we relate the presence of prefixal yi- in imperatives such as yi-dla 'eat!' to the macrostem level.
} 
In parallel with our treatment of $-a$, for which we proposed the constraint Max[FV] in (17), we invoke the constraint in (32) which mandates the surfacing of the filler suffix $-y i$.

(32) Add to D-stemRED cophonology:

$\operatorname{Max}(-y i) \quad: \quad$ Parse the $-y i$ suffix

Ranked freely with $\operatorname{Max}(\mathrm{FV})$ and $\operatorname{Max}(\mathrm{Ext})$, this constraint accounts for the new reduplication patterns we have just seen. In the input in (33), both $-a$ and $-y i$ are assumed to be present in input, just to illustrate how the constraints pick and choose among daughters of D-stemRED:

Derivation of reduplicants in dlela-dlela, dleyi-dlela, and dlayi-dlela:

\begin{tabular}{l|l||c|c|c|c|c|}
\hline dl-el-a-yi & RED $=[\sigma \sigma]$ & $\operatorname{Max}($ Root) & $\operatorname{Max}(E x t)$ & $\operatorname{Max}(F V)$ & Max(-yi) \\
\hline \hline al-el-a-yi & ${ }^{*} !$ & & & & \\
\cline { 2 - 6 } \\
b.
\end{tabular}

The candidate in (33a) loses because it violates the highest-ranked constraint, $R E D=[\sigma \sigma]$. For each of the candidates in $(33 b-d)$, there is some ranking of the bottom three constraints such that that candidate will emerge as the winner:

$$
\text { Candidate (b) wins when } \operatorname{Max}(\operatorname{Ext}), \operatorname{Max}(\mathrm{FV})>>\operatorname{Max}(y i)
$$

Candidate (c) wins when $\operatorname{Max}(y i)>>\operatorname{Max}(\operatorname{Ext})>>\operatorname{Max}(F V)$.

Candidate (d) wins when $\operatorname{Max}(\mathrm{FV}), \operatorname{Max}(\mathrm{yi})>>\operatorname{Max}(\mathrm{Ext})$.

The analysis correctly predicts that $-y i$ will not surface when the root is sufficiently large. Even if $-y i$ is present in the input, as indicated in (35), Max(Root) forbids it from supplanting root material.

(35) Max[yi] is irrelevant when root $>$ C; [yi] never supplants root material

\begin{tabular}{|c|c|c|c|c|c|c|}
\hline & lim-el-a-yi & $\mathrm{RED}=[\sigma \sigma]$ & $\overline{\operatorname{Max}(\text { Root })}$ & $\operatorname{Max}(E x t)$ & $\operatorname{Max}(\mathrm{FV})$ & $\operatorname{Max}(-y i)$ \\
\hline a. & lim-e+lim-el-a & & & *(1) & * & * \\
\hline $\mathrm{b}$ & lim-a+lim-el-a & & & $* *(\mathrm{el})$ & & * \\
\hline c. & li-yi+lim-el-a & & ${ }^{*} !(\mathrm{m})$ & $* * *(\mathrm{mel})$ & * & \\
\hline d. & 1-a-yi+lim-el-a & & ${ }^{*} ! * *(\lim )$ & $* * * *($ lime $)$ & & \\
\hline
\end{tabular}

The candidates augmented with $-y i$ in $(35 \mathrm{c}, \mathrm{d})$ are ruled out immediately by Max(Root), leaving the freely ranked $\operatorname{Max}(\mathrm{Ext})$ and $\operatorname{Max}(\mathrm{FV})$ to decide between the two attested candidates, $(35 \mathrm{a}, \mathrm{b})$.

While yielding easily to our analysis, [yi]-augmentation poses problems for the canonical stem and word-based accounts of Downing and Steriade, which we summarize in (36).
a. uku-dl-a (H) 'to eat'
uku-dl-a-yi+dl-a
b. uku-dl-el-a 'to eat for $/ \mathrm{at}^{\prime}$
uku-dl-e-yi+dl-el-a
maybe
no
no
no

RED $=$ canon. stem? RED=word?

First the reduplicant [dla-yi] in (36a) is clearly not an independent word, and is thus problematic for Steriade. [dla-yi] could be considered a canonical stem by Downing, if $-y i$ is ignored. However, in (36b), 
there is no definition of either the canonical stem or the independent word that the truncating reduplicant [dle-yi] would meet. Even if -yi is stripped off, what remains behind, namely [dl-e], is not a possible corresponding stem or word, as it contains some but not all of the applicative suffix, and no FV. ${ }^{12}$ It is because our analysis is sensitive to the internal structure of the D-stem, distinguishing roots, extension suffixes, and filler suffixes, that we are able to account for reduplication patterns in which the reduplicant contains material other than what is in the "base," including cases where it does not correspond to a possible or existing stem or word in the language.

\subsection{Subminimality and the macro-stem}

Before leaving the topic of subminimal roots, we turn to two more sets of data which provide further evidence for the view of reduplication developed in this paper. The first concerns an alternative realization of reduplicated imperatives of subminimal verbs. Consider the forms in (37).

$\begin{array}{cc}\text { Bare stem } & \text { Imperative } \\ -\mathrm{dl}-\mathrm{a} & \text { yi-dl-a } \\ -\mathrm{m}-\mathrm{a} & \text { yi-m-a } \\ -\mathrm{lw}-\mathrm{a} & \text { yi-lw-a } \\ -\mathrm{z}-\mathrm{a} & \mathrm{yi}-\mathrm{z}-\mathrm{a}\end{array}$

Reduplicated Imperative
yi-dl-a+yi-dl-a
yi-m-a+yi-m-a
yi-lw-a+yi-lw-a
yi-z-a+yi-z-a

$\begin{array}{ll} & \text { cf. from (27) } \\ \text { 'eat!' } & \text { dl-a-yi+dl-a } \\ \text { 'stand!' } & \text { m-a-yi+m-a } \\ \text { 'fight!' } & \text { lw-a-yi+lw-a } \\ \text { 'come!' } & \text { z-a-yi+z-a }\end{array}$

This method of reduplicating imperatives differs in two ways from the method seen previously. First, augmentative $y i$ - is initial, rather than final, in the reduplicant. Second, it appears also in the base.

Similar facts occur in the reduplication of bases with consonantal roots which are suffixed with the perfective -ile, which occupies the IFS position, outside the domain of reduplication. As (38a) shows, a prefixed, unreduplicated base of this sort-here, $m$-ile-is not augmentable with [yi]. Yet under reduplication, we find the same two alternatives as in the imperative: either the reduplicant is [yi]-final, and the base is not augmented, as in (38b), or the reduplicant and base are both [yi]-initial (38c).
a. (ba-) m-ile (H)
b. (ba-) m-a-yi+m-ile
'(they) stood' *(ba)-yi-m-ile
(single, suffixed -yi in reduplicant)
c. (ba-) yi-m-a+yi-m-ile
(double, prefixed yi- in reduplicant AND base)

There are two ways of thinking about the pattern in which both base and reduplicant show initial $y i$ - of the type seen in (37) and (38c):

(39) a. Reduplication: Base D-stem is prosodically augmented with yi-, which is reflected in the reduplicant

b. Backcopying: Reduplicant D-stem is prosodically augmented with yi-, which is reflected in base

One is that the presence of $y i$-is driven by a prosodic requirement on the base, being passively reflected in the reduplicant by some kind of correspondence requirement (39a). The other, in (39b), is that $y i$ - is required by the reduplicant itself, and is then required by correspondence to appear in the base as well. The latter scenario can be termed morphological "backcopying", on analogy to the transmission of phonological alternations from reduplicant to base, documented in a small number of reduplication examples by McCarthy \& Prince (1995) (but see Kiparsky 1997 and Inkelas \& Zoll 1999 for reanalyses).

${ }^{12} \mathrm{We}$ are not considering the possibility that the $[\mathrm{e}]$ of [dl-e] is interpreted as the subjunctive final vowel -e, since the base in this case is not subjunctive, and since the IFS -e never reduplicates under any condition. 
The evidence would appear to favor backcopying in this instance. First, it would be difficult to maintain the base-augmentation analysis in (30a), given our earlier finding that prosodic minimality is enforced on reduplicants and on whole words but NOT otherwise on verb stems, as was schematized in (26). Recall that the evidence for this was the behavior of unreduplicated monosyllabic verb stems, as in (28): these are not supplemented by [yi]. If the stem formed a domain for prosodic minimality, an assumption necessary to maintain the analysis in (39a), then the facts in (37) and (38) would be unexplained.

The second piece of evidence for backcopying comes from the behavior of bases preceded by a prefixal object marker (OM), e.g. noun class $10 z i-$, the one used in all examples herein. If, and only if, the root of a reduplicated stem is consonantal, then $z i$ - (and other OMs) can be reduplicated, appearing in both reduplicant and base. In (40) we present a case of OM doubling where the consonantal root is not followed by extension suffixes. The reduplicant is enclosed in brackets:

(40) Object marker (OM) -zi- can be doubled under reduplication, but only with C- roots

$$
\begin{array}{lll}
\text { uku-zi-dl-a }(\mathrm{H}) \text { 'to eat them' } & \text { uku-zi-[dl-a-yi]+dl-a } & (\mathrm{OM} \text { is not reduplicated }) \\
& \mathrm{uku}-[\mathrm{zi}-\mathrm{dl}-\mathrm{a}]+\mathrm{zi}-\mathrm{dl}-\mathrm{a} & (\mathrm{OM} \text { is reduplicated })
\end{array}
$$

These data are quite parallel to the yi-prefixation data seen earlier: exactly when there is room in the reduplicant for the OM, the OM may appear doubled in the base. Its appearance in the reduplicant is being driven by the bisyllabic prosodic size requirement on the reduplicant; the base (here, $d l-a)$ would be well formed without the OM, but the reduplicant would not.

Unlike prefixal yi-, OM's can be incorporated into the bisyllabic reduplicant, and "backcopied", even when the consonantal root is followed by extension suffixes. As (41) shows, in such cases, the reduplicant can be brought up to two syllables by incorporating either the OM, the extension suffix, the FV - $a$ (or both), OR suffixal -yi can be used to bring the reduplicant up to two syllables:
a. uku-zi-dl-el-a $(\mathrm{H})$ 'to eat them for $/$ at'

b. uku-zi-dl-is-a (H) 'to feed them'

c. uku-zi-thum-a $(\mathrm{H})$ 'to send them'
uku-zi-[dl-el-a]+dl-el-a
uku-zi-[dl-a-yi]+dl-el-a
uku-zi-[dl-e-yi]+dl-el-a
uku-[zi-dl-a]+zi-dl-el-a
uku-[zi-dl-e]+zi-dl-el-a
(OM not reduplicated)
(OM is reduplicated)
uku-zi-[dl-is-a]+dl-is-a
uku-zi-[dl-a-yi]+dl-is-a
uku-zi-[dl-i-yi]+dl-is-a
uku-[zi-dl-a]+zi-dl-is-a
uku-[zi-dl-i]+zi-dl-is-a
(OM not reduplicated)
(OM is reduplicated)
uku-zi-[thum-a]+thum-a
*uku-[zi-thu]+zi-thum-a

As seen in (42), the only option for fleshing out the reduplicant which is not available in these verbs with OM's is prefixal yi-. Prefixal yi- is in complementary distribution with OM's.

Prefixal yi- may not occur in verbs (reduplicated or otherwise) with OMs

*uku-zi-[yi-dl-a]+yi-dl-a (intended: 'to eat them')

We thus add the OM, if present in the verb, to the list of options for fleshing out the bisyllabic DstemRED constituent: 
(43) Potential daughters of D-stemRED:
a. Root
b. Extension suffixes
c. $\mathrm{FV}-a$
d. Suffixal -yi
e. Prefixal yi-
f. OMs
entails backcopying; in complementary distribution with $\mathrm{OM}$ entails backcopying; in complementary distribution with prefixal yi-

Note in (41c) that the OM cannot appear in reduplicants whose root is CVC or longer (cf. the correct output, uku-zi-thuma-thuma, where the OM zi-is not included in the bisyllabic reduplicant, thum-a). This follows from our existing analysis. Since reduplicants are required by the high-ranking $\operatorname{MAX}$ (Root) to exhaust the first CVC portion of the root, in such a case there is no room for any affixes in the reduplicant:

$z i$ - not doubled when root $>C$

\begin{tabular}{|c|c|c|}
\hline zi-thum-a & {$[\sigma \sigma]$} & MAX (Root) \\
\hline zi-thum-a+thum-a & & \\
\hline zi-thu+zi-thum-a & & ${ }^{*} !(\mathrm{m})$ \\
\hline
\end{tabular}

At this point in the analysis, three questions arise:

(45) a. Why are OMs in complementary distribution with prefixal yi-?

b. Why are only OMs and prefixal yi- "backcopied" to the base?

c. What is the morphological analysis of backcopying?

Our analysis is the following. First, we propose that OMs and prefixal yi- occupy the same morphological "slot". They are prefixes which attach to D-stems to create a constituent which Bantuists refer to as the Macrostem (M-stem):

$$
\text { Prefix D-stem Where Prefix }=\text { OM or } y i-
$$

Prefixal yi- may be semantically empty, but has a morphological effect nonetheless: constituents containing it must be of the level M-stem. ${ }^{13}$

Given the structure in (46), our next step is to generalize the reduplication construction. In addition to consisting of juxtaposed D-stems, we now allow the R-stem to consist of juxtaposed M-stems. The juxtaposed stems in the reduplication construction must still agree in every feature-including morphological category (D-stem vs. M-stem).

\section{Modified Rstem construction:}

${ }^{13}$ In proposing that OMs belong to a Macrostem constituent that excludes the IFS, we depart from the tradition of analyzing them as sisters to the I-stem. Note that a number of Bantu languages treat noun class-marked prefixes such as OMs specially if they "fuse" with the root into the initial syllable of the D-stem. In Kirimi, Schlindwein (1986) provides several arguments that the first person singular prefix, a homorganic nasal, actually belongs to the stem. Among these is the observation that in a number of Bantu languages which otherwise restrict the prefix slot to one $\mathrm{OM}$, the first person singular prefix can still co-occur with a second OM. A reasonable conclusion to draw is that it joins the stem, thereby freeing up the one prefix slot for a second OM. 


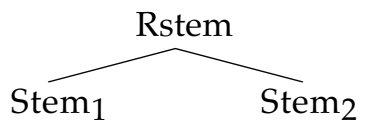

where Stem 1 and Stem 2 can be either D-stems or M-stems, so long as they agree in every morphological feature (including category)

We can now understand why it is the prefixal supplements to the reduplicant that induce backcopying: they induce it by requiring the reduplicant to be an M-stem. Due to the highly agreeing nature of the reduplication construction, if the reduplicant is an M-stem, the base must be as well-and when the base is an M-stem, it of course MUST have a prefix. Once it is established that both reduplicant and base must are M-stems, it is a simple matter of morphosyntactic feature checking to ensure that they each have the SAME prefix. Thus, OM doubling is NOT in fact backcopying, but rather simple reduplication.

The components involved in the apparent backcopying of an OM are recapitulated in (48).

Components involved in "doubling" of OM:

a. Morphology allows free choice of M-stem or D-stem reduplication constructions

b. If M-stem construction is chosen, the obligatory prefix (an $\mathrm{OM}$ or $y i^{-}$) is parsed into reduplicant

c. Morphosyntactic feature agreement between reduplicant and base ensures that reduplicant and base end up with the same prefix

The M-stemRED cophonology is the same as the D-stemRED cophonology, with one exception: the MstemRED cophonology contains a constraint requiring the prefix to be parsed:

$$
\begin{aligned}
& \text { M-stemRED cophonology } \\
& \operatorname{Max}(\operatorname{Pfx}), \operatorname{Max}(\text { Root) are inviolable }
\end{aligned}
$$

The inviolable nature of both constraints means that if the root is longer than $\mathrm{C}$, the M-stem reduplication construction cannot be used. This is a correct prediction. ${ }^{14}$

In summary, we have examined further data which confirm our claim that the reduplicant is morphologically complex. We have shown that the truncation-agreement analysis of reduplication can extend nicely to these new data, including to the apparent "backcopying" phenomena which results when the reduplicant is prefixed.

By contrast, the canonical stem and corresponding word analyses of Downing and Steriade have little to say about these data. Certainly reduplicants with initial yi- (e.g. yi-dl-a) are not "canonical stems"; nor are the truncated reduplicants with initial $z i-($ e.g. $z i-d l-i, z i-d l-a)$ possible words. ${ }^{15}$

\footnotetext{
${ }^{14}$ The other option for generating backcopying would be to assume a phonological correspondence between reduplicant and base, following McCarthy \& Prince (1993, 1995), and use an anchoring constraint. This would capture the generalization that the affixes which force backcopying are both prefixes:

ANCHOR-L : The initial elements of RED and Base must correspond.

${ }^{15}$ We have chosen these forms to highlight that there is no correpondence to existing words, even if the final -i or -a is taken to be inflectional: In Ndebele, as in many Bantu languages, when an (affirmative) imperative verb is preceded by an OM, the IFS that must be used is -e, hence: zi-dl-e 'eat them!'.
} 
(50) Forms not amenable to canonical stem or possible word analysis:
a. uku-zi-dl-is-a 'to feed them'
uku-zi-dl-i+zi-dl-is-a (zi-dl-i $\neq$ possible stem or word)
b. uku-zi-dl-is-a 'to feed them'
uku-zi-dl-a+zi-dl-is-a $\quad(z i-d l-a \neq$ possible stem or word $)$

We next consider imbricated verb stems, which provide further support for our analysis.

\section{Imbrication}

In this section we consider the reduplication of verb stems that have undergone imbrication, a special fusion process triggered by the perfective suffix -ile.

Whereas most CVC roots add -ile in the perfective, as seen to the right in (51a),

(51) a. regular suffixation of -ile in the perfective

$\begin{array}{lll}\text { lim-a } & \text { 'cultivate' } & \text { ba-lim-ile 'they cultivated' } \\ \text { thum-a }(H) & \text { 'send' } & \text { ba-thum-ile 'they sent' }\end{array}$

b. fusion (or "imbrication") of perfective -ile, causing "umlaut" of / a / $\rightarrow[\mathrm{e}]$

bonakal-a (H/L) 'appear, be visible' ba-bonakel-e 'they appeared, were visible'

dumal-a (H/L) 'become depressed' ba-dumel-e 'they became depressed'

thath-a (H) 'take' ba-theth-e 'they took'

others such as those in (51b) instead fuse or "imbricate" the -il-part of the perfective ending -ile. In these examples, the penultimate root vowel [a] is realized as [e], and the stem also ends in the final vowel $-e .{ }^{16}$ The question is how the "umlaut" in (51b) affects reduplication.

As seen in $(52 a)$,
a. ba-bonakel-e (H/L) 'they appeared'
ba-bona+bonakel-e
b. ba-dumel-e $(\mathrm{H} / \mathrm{L})$ 'they became depressed' ba-duma-dumele
ba-dume-dumele
c. ba-theth-e (H) 'they took'
ba-thath-a+theth-e
ba-theth-a+theth-e
*ba-theth-e+theth-e

since the reduplicant is bisyllabic, imbrication has no effect on the reduplicant when the umlauted penultimate vowel does not occur in one of the first two syllables of the stem. In (52b), however, where imbrication affects the second vowel of the root dumal-, converting it to dumel-, we see that the reduplicant can be either duma- or dume-. Similarly, in (52c), where imbrication converts the root thath- to theth-, there are again two possible reduplicants: thatha- and thetha-. The reduplicant thethe-, on the other hand, is not grammatical. The correct observation is that the "umlaut" triggered by the perfective can be reduplicated, while the final $-e$ of the perfective cannot be.

Note in the case of $a-d u m a+d u m e l-e$ in (52b), that the reduplicant duma- is not an existing minimal canonical stem. So it cannot be the case that the sequence -ele of -dumele is simply being truncated. Instead, to account for the perfective, we recognize two "alloconstructions". The first, schematized in (53), shows the non-imbricating alternate:

\footnotetext{
${ }^{16}$ In these verb stems forms we do not show frozen morpheme breaks, e.g. bon-akal- or bon-ak-al-. These do not bear on the treatment of the imbricated forms, which derive historically from *bonakail-e, *dumail-e, and *thaith-e. See Bastin (1983) and Hyman (1995) for further evidence and discussion.
} 
(53) Non-imbricating perfective:

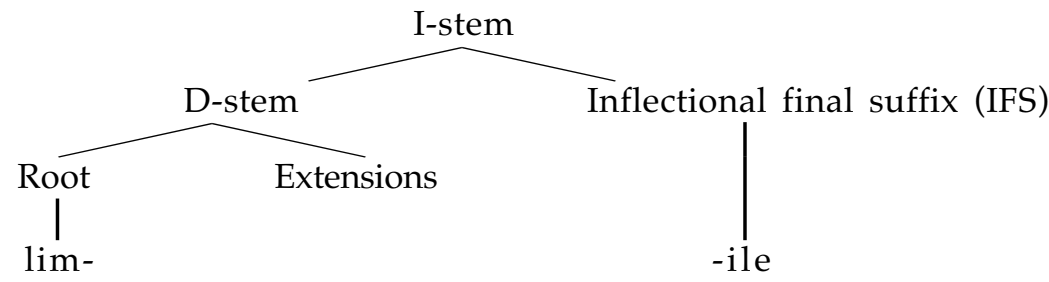

As shown, the non-imbricating -ile suffix is unambiguously in the IFS position, hence unavailable for reduplication.

Now consider the analysis of perfectives marked by $-e$ with umlaut. ${ }^{17}$ The question is where the umlauting feature (") should be within the morphosyntactic structure, since it optionally appears in the reduplicants in $(52 b, c)$. Our view is that Ndebele speakers themselves are not sure where to assign the umlaut, and hence have the two competing analyses, schematized in (54).

(54) a. Imbricating perfective: umlaut analyzed to be part of IFS

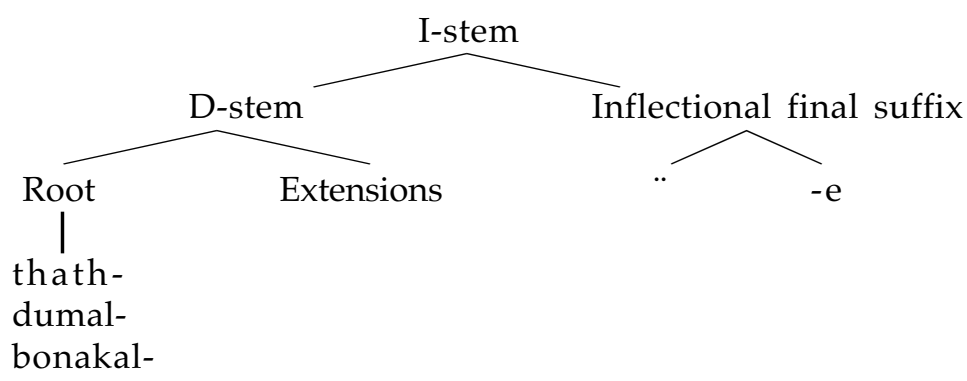

b. Imbricating perfective: umlaut analyzed to be part of D-stem (e.g. root)

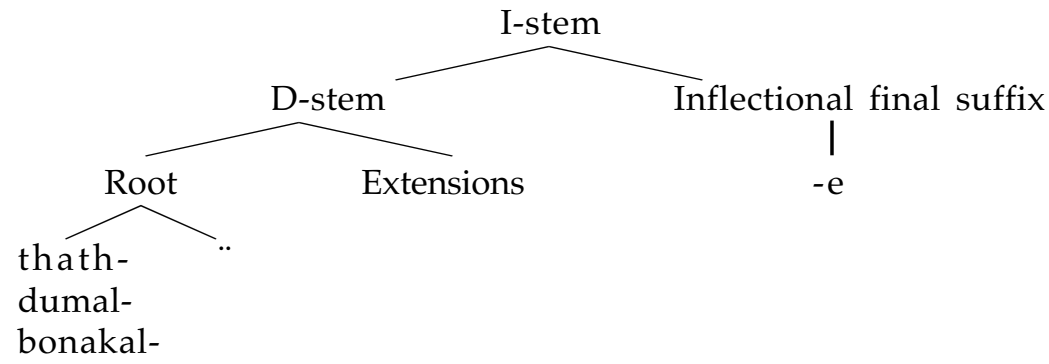

In (54a), the umlaut is assigned to the IFS, identically to -ile in (53), from which it clearly derives historically. In (54b), however, the umlaut is seen as an internal modification on the morpheme to which it attaches-here, the root. ${ }^{18}$ If assigned the structure in (54a), the umlaut will not be realized

${ }^{17}$ It should be pointed out that some verbs do not accept the imbricated form, while still others show variability. In addition, verbs whose last vowel is other than / a may also take the "short" -e form in the perfective, but in these cases there is no umlaut, e.g. a-dabul-ile = a-dabul-e 'he tore'.

${ }^{18}$ An alternative would be to analyze the umlaut as an "extension", where it would be optionally parsed under reduplication, exactly like applicative -el- and causative -is-. While this works for the perfective, it does not generalize to the passive construction analyzed in $\S 4$. We therefore prefer to say that speakers are inconsistent in assigning the umlauting feature to either the IFS or to the D-stem, as in $(54 a, b)$. The one exception is where the umlaut is assigned to an extension with /a/, e.g. thum-an-a 'send each other' $\rightarrow$ ba-thum-en-e 'they sent each other'. In this case the umlaut is assigned to -an-, i.e. under the extension node in (54b). 
in the reduplicant, which bars the realization of inflectional features. If assigned the structure in (54b), umlaut will be obligatorily realized because of the high ranking constraint MAX(Root). In neither case will the final suffix -e make it into the reduplicant, since it is unambiguously an IFS.

Finally, for the sake of completeness, note in (55) that reduplicated verbs optionally are exempt from imbrication even when their non-reduplicated forms must imbricate:
a. ba-bona+bonakal-ile
(H/L) 'they appeared'
*ba-bonakal-ile
(cf. 52a)
b. ba-duma+dumal-ile
$(\mathrm{H} / \mathrm{L})$ 'they became depressed'
*ba-dumal-ile
(cf. 52b)
c. ba-thath-a+thath-ile
(H) 'they took'
*ba-thath-ile
(cf. 52c)

We hypothesize that these forms arise in the following way. First, we note that imbrication is not automatic in Ndebele. For example, of the $148 \mathrm{CaCaC}$ - verb roots in the Comparative Bantu On-Line Dictionary (CBOLD) version of Pelling (1971), 39 obligatorily undergo imbrication and 24 do so optionally, while 85 may not imbricate. Roots (and extension morphemes such as the reciprocal -an-) will therefore have to carry lexical marking for imbrication. This lexical marking only optionally percolates up to the R-stem level. When it is present, the appropriate match with the IFS -e will be made. When it is absent, -ile must be used. ${ }^{19}$

To summarize, with this last assumption, as well as the two "alloconstructions" in (54), imbrication supports the analysis we have developed thus far. Reduplication is juxtaposition of morphologically identical stems (either M-stems or D-stems), with the first subject to a bisyllabic size condition.

\section{Palatalization}

In the last two sections we have established that affixal material in the D-stem may surface in the reduplicant only when the verb root has been exhaustively parsed. We now consider passivized forms, which further support this conclusion and make more precise our proposals about the internal structure of the reduplicant.

In (56a) we see that the passive is derived by means of the derivational suffix $-w-$, here occurring directly after the root:

(56) Passive - $\mathrm{w}$ - causes preceding labial to palatalize

\begin{tabular}{|c|c|c|}
\hline $\begin{array}{l}\text { bal-a 'read' } \\
\text { bik-a (H) } \\
\text { phek-a 'cook' }\end{array}$ & $\begin{array}{l}\text { bal-w-a } \\
\text { 'announce' } \\
\text { phek-w-a }\end{array}$ & $\begin{array}{l}\text { 'be read' } \\
\text { bik-w-a 'be announced' } \\
\text { 'be cooked' }\end{array}$ \\
\hline $\begin{array}{l}\text { boph-a }(\mathrm{H}) \text { 'tie' } \\
\text { bumb-a }(\mathrm{H}) \text { 'mould' } \\
\text { thum-a }(\mathrm{H}) \text { 'send' }\end{array}$ & $\begin{array}{l}\text { botsh-w-a } \\
\text { bunj-w-a } \\
\text { thuny-w-a }\end{array}$ & $\begin{array}{l}\text { 'be tied' } \\
\text { 'be moulded' } \\
\text { 'be sent' }\end{array}$ \\
\hline
\end{tabular}

The examples in (56b) show that this $-w$ - palatalizes an immediately preceding labial consonant. However, as the examples in (57) show, palatalization is not restricted to the immediately preceding consonant, but can target any preceding labial, as long as it is not the first consonant in the constituent: ${ }^{20}$

\footnotetext{
${ }^{19}$ Further documentation and discussion will be available in Sibanda (in preparation).

${ }^{20}$ The imperviousness of morpheme-initial labials to palatalization has been addressed by Chen \& Malambe (1998), Downing (to appear), and Sibanda (1999a); we will pay it no further attention here.
} 
(57)

Palatalization operates at-a-distance:

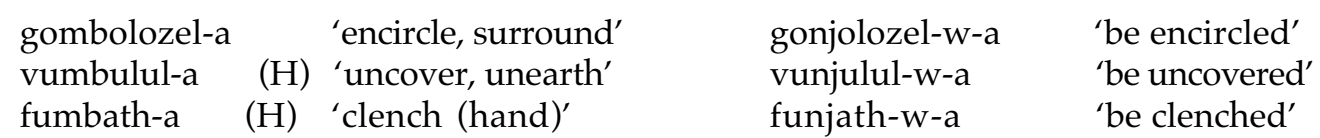

Like the imbricating alternant of the perfective, we follow Sibanda $(1996,1999$ a) in analyzing the passive as having two phonological components. Basing himself on Zoll (1996), Sibanda characterizes these as subsegments, one palatalizing (call it $\pi$ ) and the other labializing (call it $\omega$ ). The palatalizing component attaches, potentially over some distance, to a preceding labial consonant and changes its place of articulation to palatal. The labializing component attaches to the immediately preceding consonant and gives it a labial offglide.

Now consider the possible reduplicated forms of the verbs in (58).

(58) Passive $-w$ - optionally appears in reduplicant, but palatalization is obligatory

\begin{tabular}{|c|c|c|c|c|}
\hline \multirow[t]{3}{*}{ a. } & 'read' & bal-w-a & 'be read' & $\begin{array}{l}\text { bal-w-a+bal-w-a } \\
\text { bal-a+bal-w-a }\end{array}$ \\
\hline & bik-a (H) 'announce' & bik-w-a & 'be announced' & $\begin{array}{l}\text { bik-w-a+bik-w-a } \\
\text { bik-a+bik-w-a }\end{array}$ \\
\hline & phek-a 'cook' & phek-w-a & 'be cooked' & $\begin{array}{l}\text { phek-w-a+phek-w-a } \\
\text { pek-a+phek-w-a }\end{array}$ \\
\hline b. & boph-a (H) 'tie' & botsh-w-a & 'be tied' & $\begin{array}{l}\text { botsh-w-a+botsh-w-a } \\
\text { botsh-a+botsh-w-a } \\
\text { *boph-a-botsh-w-a }\end{array}$ \\
\hline & bumb-a $\quad(\mathrm{H})$ 'mould' & bunj-w-a & 'be moulded' & $\begin{array}{l}\text { bunj-w-a+bunj-w-a } \\
\text { bunj-a+bunj-w-a } \\
\text { *bumb-a+bunj-w-a }\end{array}$ \\
\hline & thum-a $(\mathrm{H})$ 'send' & thuny-w-a & 'be sent' & $\begin{array}{l}\text { thuny-w-a+thuny-w-a } \\
\text { thuny-a+thuny-w-a } \\
\text { *thum-a+thuny-w-a }\end{array}$ \\
\hline
\end{tabular}

In each case the -w- may or may not appear in the reduplicant, exactly as we expect of a derivational suffix. However, any labial palatalization induced by the passive obligatorily surfaces in the reduplicant (cf. the ungrammaticality of *thum-a+thuny-w-a etc.). (59).

The same facts are obtained when the final vowel is other than $-a$, for example, subjunctive $-e$ in

(59) Same facts when FV is $-e(-i$, or $-i l e)$

\begin{tabular}{|c|c|c|c|}
\hline \multirow[t]{3}{*}{ a. } & bal-w-e & 'be read' (subjunctive) & $\begin{array}{l}\text { bal-w-a+bal-w-e } \\
\text { bal-a+bal-w-e }\end{array}$ \\
\hline & bik-w-e & 'be announced' & $\begin{array}{l}\text { bik-w-a+bik-w-e } \\
\text { bik-a+bik-w-e }\end{array}$ \\
\hline & phek-w-e & 'be cooked' & $\begin{array}{l}\text { phek-w-a+phek-w-e } \\
\text { pek-a+phek-w-e }\end{array}$ \\
\hline b. & botsh-w-e & 'be tied' & $\begin{array}{l}\text { botsh-w-a+botsh-w-e } \\
\text { botsh-a+botsh-w-e } \\
\text { *boph-a-botsh-w-a }\end{array}$ \\
\hline
\end{tabular}




$\begin{array}{lll}\text { bunj-w-e 'be moulded' } & \begin{array}{l}\text { bunj-w-a+bunj-w-e } \\ \text { bunj-a+bunj-w-e } \\ \text { *bumb-a+bunj-w-e } \\ \text { thuny-w-a+thuny-w-e } \\ \text { thuny-w-e }\end{array} \quad \begin{array}{l}\text { thuny-a+thuny-w-e } \\ \text { *thum-a+thuny-w-e }\end{array}\end{array}$

Treating the passivizing $\pi$ and $\omega$ as subsegments under the D-stem parallels our analysis of the umlauting subsegment "that results in imbrication, as discussed earlier. Two important differences subdivide this set of subsegments, however. First, while $\omega$ and " are constrained to appear on the immediately preceding segment (the preceding consonant and /a/, respectively), $\pi$ is permitted to find suitable hosts anywhere within the D-stem. We state this as difference with respect to the adjacency constraint in (60).

(60) $\omega$ and ", but not $\pi$, is subject to morphological ADJACENCY (alignment), i.e. the output segment on which it surfaces must correspond to the rightmost $\mathrm{C}$ or $\mathrm{V}$ of the immediately preceding morpheme in the input

This condition draws support from the data in (61), in which the root is longer than CVCV and must therefore be truncated in the reduplicant.

(61) When root is truncated, passive $\omega$ does not surface in reduplicant

\begin{tabular}{|c|c|c|}
\hline $\begin{array}{l}\text { gombolozel-a } \\
\text { vumbulul-a } \\
\text { fumbath-a }\end{array}$ & $\begin{array}{l}\text { 'encircle, surround' } \\
\text { 'uncover, unearth' } \\
\text { 'clench (hand)' }\end{array}$ & $\begin{array}{l}\text { gombo+gombolozel-a } \\
\text { vumbu+vumbulul-a } \\
\text { fumba+fumbath-a }\end{array}$ \\
\hline $\begin{array}{l}\text { gonjolozel-w-a } \\
\text { vunjulul-w-a } \\
\text { funjath-w-a }\end{array}$ & $\begin{array}{l}\text { 'be encircled' } \\
\text { 'be uncovered' } \\
\text { 'be clenched' }\end{array}$ & $\begin{array}{l}\text { gonjo+gonjolozel-w-a } \\
\text { vunju+vunjulul-w-a } \\
\text { funja+funjath-w-a } \\
{ }^{\text {f }} \text { funj-w-a+funjath-w-a }\end{array}$ \\
\hline
\end{tabular}

Although these are passive stems, the passive $\omega$ is not able to surface in the reduplicant. The impossibility of passive $\omega$ in these reduplicants follows straightforwardly from ADJACENCY: the final consonant of the root does not surface in the reduplicant, and therefore, by the terms of ADJACENCY, the passive $-w$ - cannot surface either.

As a control, the data in (62) show that labialization which is not from the passive morpheme must be preserved under reduplication:
a. yejwayel-a
'get accustomed to'
yejwa+yejwayel-a
yejwa+yejwayez-a
*yeja+yejwayel-a
yejwayelek-a
yejwayez-a
'become customary'
yejwa+yejwayelek-a
*yeja+yejwayelek-a
yenway-a
'accustom'
yenwa+enway-a
*yeja+yejwayez-a
'scratch an irritation'
*yena+yenway-a
b. yenwab-a
'be happy' (= wonwab-a) yenwa+yenwab-a
*yena+yenwab-a
wonwab-a
'be happy' (= yenwab-a)
wonwa+wonwab-a
*wona+wonwab-a
c. qwaqwaz-a 'click (stick on stick)'
tshwatshwaz-a 'make hissing noise'
qwaqwa+qwaqwaz-a *qwaqa+qwaqwazw-a tshwatshwa+tshwatshwaz-a
*tshwatsha+tshwatshwaz-a

It is not optional to copy only the $\mathrm{C}$ portion of a tautomorphemic $\mathrm{Cw}$ structure. ${ }^{21}$

21 The forms in (62) are the only examples we know where tautomorphemic $\mathrm{Cw}$ is found in post-steminitial position. Since the glides of initial [ye] and [wo] in $(62 a, b)$ can be treated as epenthetic, the 
The second dimension of difference among the three subsegments is why imbricating " and passivizing $\omega$ are only optionally parsed in the reduplicant, while passivizing $\pi$ must surface (assuming, of course, that a suitable host exists in the output). Our approach taken to imbrication in $\S 4$ readily provides an explanation. Optionality in the case of " was said to result from the availability of the two alloconstructions in (54): When " is taken to be part of the IFS, it cannot appear in the reduplicant. When it is taken, instead, to belong to the same constituent as the segment on which it is realized, i.e. the root, it must be parsed into the reduplicant. In the passive case, there is only one construction: When a root labial is palatalized, $\pi$ belongs to the root and hence must appear in the reduplicant because of high-ranked $\operatorname{Max}(\operatorname{Root})$.

To recapitulate what we have said about the passive thus far, $\pi$ obligatorily appears in the reduplicant because it is parsed with the root on which its palatalizing effect is realized. On the other hand, $\omega$ was said to optionally occur in the reduplicants in (58) and (59) because it is a derivational affix which can be truncated as in the case of applicative -el-and causative -is-. However, close inspection of more morphologically complex forms shows that additional, and more interesting, conditions hold on the surfacing of the passive $\omega$ subsegment.

Consider in particular the passivized applicative stems in (63). The applicative extension suffix -el- occurs between the root and the passive suffix. Note the expected long-distance action of the palatalizing component $\pi$ of the passive in the nonreduplicated stems in (63b):

Applicative -el- between root and passive -w-:

a. bal-el-a 'read for $/ \mathrm{at}^{\prime}$ bik-el-a (H)

for $/ \mathrm{at}^{\prime}$

$$
\text { phek-el-a 'cook for / at' }
$$

b. boph-el-a (H) 'tie for/at' bumb-el-a (H) 'mould for / at' thum-el-a (H) 'send for / at' bal-el-w-a 'be read for/at' 'announce for/at' bik-el-w-a 'be announced phek-el-w-a 'be cooked for/at' botsh-el-w-a 'be tied for $/ \mathrm{at}^{\prime}$ bunj-el-w-a 'mould for/at' thuny-el-w-a 'be sent for/at'

Up to now we have not seen a case in which two semantically contentful suffixes jockey for a position in the reduplicant. Which will take precedence? Will there be free variation, as we have seen between extension suffixes and the "filler " morphs [yi] and [a]? The forms in (64) show the reduplicated versions of the passivized applicatives in (63). As seen earlier in the unextended stems, the palatization component $\pi$ of the passive surfaces in the reduplicant, while the labial component $\omega$ is optional:

(64) Passive $\omega$ optionally appears in truncated RED

\begin{tabular}{|c|c|c|}
\hline bal-el-w-a & 'be read for $/ \mathrm{at}^{\prime}$ & $\begin{array}{l}\text { bal-e+bal-el-w-a } \\
\text { bal-a+bal-el-w-a } \\
\text { bal-w-a+bal-el-w-a }\end{array}$ \\
\hline bik-el-w-a & 'be announced for $/ \mathrm{at}^{\prime}$ & $\begin{array}{l}\text { bik-e+bik-el-w-a } \\
\text { bik-a+bik-el-w-a } \\
\text { bik-w-a+bik-el-w-a }\end{array}$ \\
\hline phek-el-w-a & 'be cooked for/at' & $\begin{array}{l}\text { phek-e+phek-el-w-a } \\
\text { phek-a+phek-el-w-a } \\
\text { phek-w-a+phek-el-w-a }\end{array}$ \\
\hline
\end{tabular}

correct generalization may be that tautomorphemic /w/ appears only after the first consonant of a stem. See Sibanda 1999. 


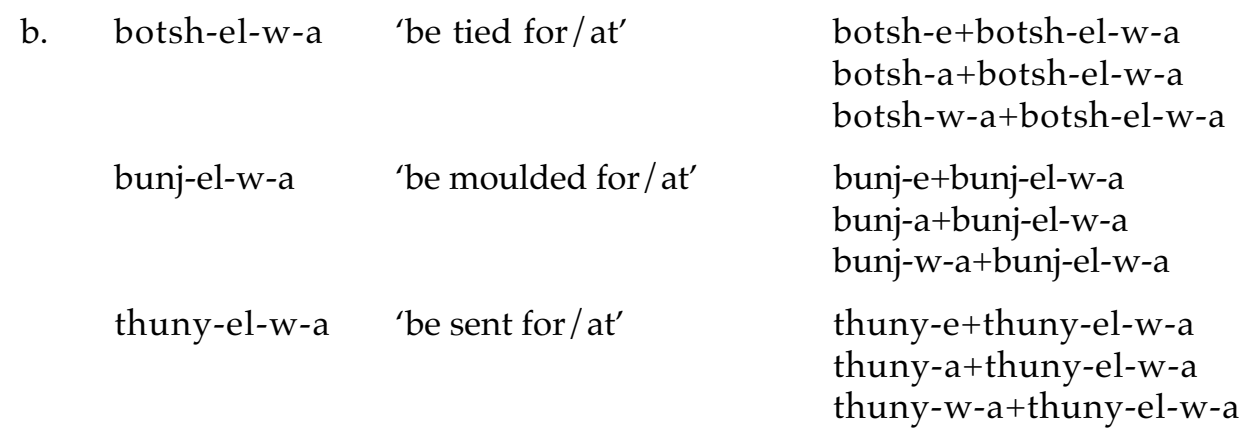

Note that when the passive $\omega$ does surface in these reduplicants, it surfaces on a segment to which it is not adjacent in the input, in apparent violation of the ADJACENCY constraint proposed earlier. That is, it appears that a mapping such as that in (65) is occurring: the passive is surfacing not on the final segment of the immediately preceding morpheme, but on the final segment of the morpheme before that. The applicative suffix is being skipped over, even though it is closer to the beginning of the stem and (under standard assumptions about multiply extended D-stems) forms a closer constituent with the root than the passive does:

(65) Passive $\omega$ appears to surface on a segment which does not end the immediately preceding morpheme, in violation of ADJACENCY:

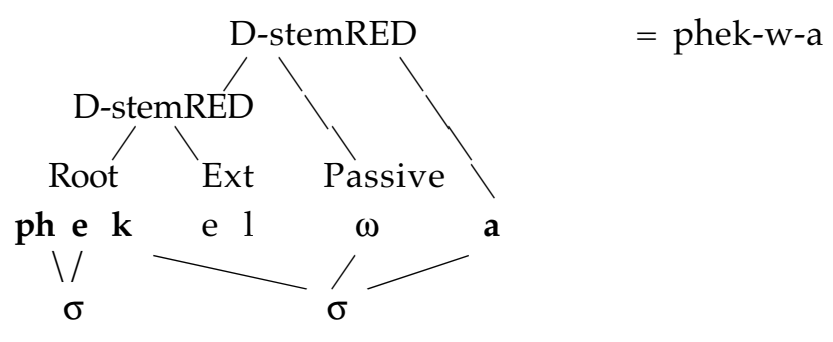

Is ADJACENCY violable in Ndebele? We suggest that it is not. Rather, we contend that the appearance of "at-a-distance" linking of passive $\omega$ in (65) is illusory, and that the applicative is not in fact being skipped over in these cases.

In order to appreciate this contention, consider the data in (66), which serve as background to a previously undetected morphological condition on the surfacing of passive $\omega$ in reduplicants. The verbs in both sentences in (66) contain the sequence $-e l-w-$, composed of applicative and passive extension suffixes:
a. abantwana
b-a-phek-el-w-a
ukudla
children they-past-cook-appl-pass food
b. ukudla
kw-a-phek-el-w-a it-past-cook-appl-pass
abantwana children
'the children were cooked food'
'the food was cooked (for) the children'

Although possessing the same surface morphs in the same linear order, these verb stems realize two different argument structures. The sentence in (66a) is a passivized applicative, and its verb has the argument structure in (67a). 
(67)

a.

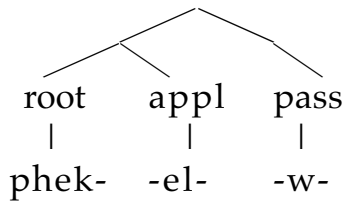

's.o. be cooked for sth.' b.

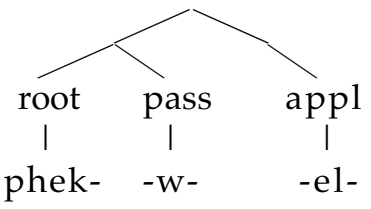

'sth. be cooked for s.o.'

This morphological structure and this order of the suffixes is what is expected from the scope relations or "mirror principle" (Baker 1985, Alsina 1999, Hyman \& Mchombo 1992). The sentence in (66b), on the other hand, is an applicativized passive, and its verb has the argument structure in (67b). In this case, by the mirror principle, the order of the morphs is expected to be passive $-w$-followed by applicative -el-. However, in Ndebele, as in most Bantu languages, the applicative cannot follow the passive. ${ }^{22}$ Hence, a number of linguists, particularly of the Tervuren school inspired by Meeussen, have proposed rules that metathesize morphs, as in (68).

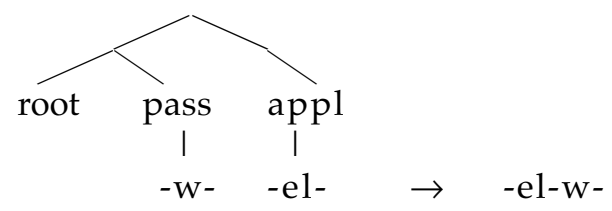

It is not the surface order of the morphs that interests us, but rather the underlying morphosyntactic structure. Given this, now consider how the verbs in (66) reduplicate:
a. abantwana
b-a-phek-e+phek-el-w-a
ukudla
'the children were cooked food'
b-a-phek-a+phek-el-w-a
*b-a-phek-w-a+phek-el-w-a
b. ukudla
kw-a-phek-e+phek-el-w-a abantwana
kw-a-phek-a+phek-el-w-a
kw-a-phek-w-a+phek-el-w-a
'food was cooked for the children'

In (69a), the passivized applicative, we see that the reduplicant can be pheke- or pheka-, but not * phekwa. Passive $\omega$ can not be parsed in the reduplicant. In (69b), by contrast, the reduplicant can be phek-e+, phek-a+, or phek-w-a+. The reduplicant is free to parse $\omega$ or not, as we are used to seeing.

The reason for this surprising discrepancy jumps out once one compares the argument structures of the verb stems in (67): The passive surfaces under reduplication only if it is sister to the root. Thus, phek-w-a+ is well-formed as the reduplicant of -phek-el-w-a only if the subtree root+passive occurs in the base to which it corresponds, as in $(67 \mathrm{~b})$. We conclude that reference to internal morphosyntactic structure is critical to determining the well-formedness of reduplicants. ${ }^{23}$

How exactly is this reference to be made? We posit that it follows as a direct consequence from the internal structure of the Ndebele verb stem. Making the standard assumption that D-stems are binary branching, (70) gives the structure of the reduplicant of an extended verb stem of the kind seen above: ${ }^{24}$

\footnotetext{
${ }^{22}$ For a comprehensive study of verb extension combinations in Ndebele, see Sibanda (1999b), where it is shown that the "morphotactically unmarked" linear order is -is-el-an-w- (causative-applicativereciprocal-passive).

${ }^{23}$ For discussion of other cases in the Bantu verb stem where the order of surface morphs does not correspond to the underlying morphosyntactic structure, see Hyman $(1994,1998)$.

${ }^{24}$ For an earlier proposal to regard each (cyclic) suffixation as creating a D-stem, see Downing's (1997c) account of reduplication of Kikerewe, based on Odden 1996).
} 
(70) Reduplicant of passivized applicative verb stem:

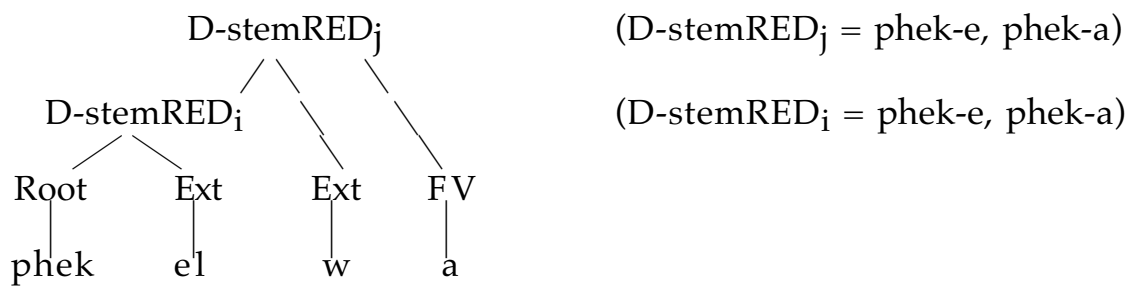

Whether it is D-stemRED $\mathrm{j}_{\mathrm{j}}$ or $\mathrm{D}$-stemRED $\mathrm{D}_{\mathrm{i}}$ that is spelled out, only two reduplicants are possible: phek$e$ and phek-a. The candidate phek-w-a is ruled out because of the ADJACENCY violation that results from skipping over the applicative -el-. On the other hand, in the case of applicativized passives, we would have a structure like the one in (71), in which the lowest D-stem node has the passive suffix adjacent to the root:

(71) Reduplicant of applicativized passive:

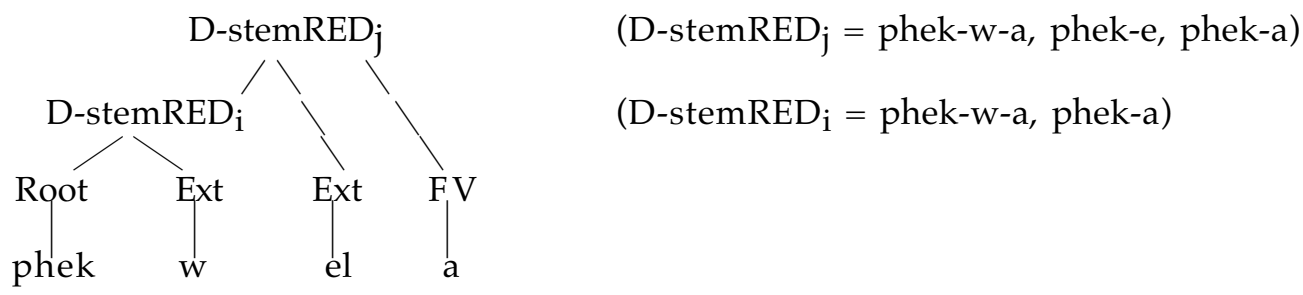

As seen, both phek-w- $a$ and phek- $a$ can be spelled out as the reduplicant at both the D-stemREDj and $\mathrm{D}$-stemREDi levels, while phek-e can result only as the realization of D-stemRED $\mathrm{D}_{\mathrm{j}}$ Note that phek$w$-e is not a possible reduplicant, since the morphotactics prohibit the [e] of applicative -el-from following passive $-\mathrm{w}$ - on the surface.

As seen, in the D-stemRED cophonology in both (70) and (71), copying of labialization is optional, but ADJACENCY is always respected. Thus the passive - $w$ - can, but need not, be parsed at the lowest Dstem RED node, where the segment to which it would be adjacent in output ends the immediately preceding morpheme in the input.

Observe that the branching structure we hypothesize for the Bantu verb stem, both "base" and "reduplicant", is tantamount to a cyclic analysis. Constraints are enforced on every incarnation of a Dstem (or M-stem), regardless of whether it is a daughter or a mother in the verb structure. This effect is predicted by the theory of Sign-Based Morphology (Orgun 1996) and is particularly evident in cases where one valency demands one vs. another order of suffixation. In the example in (72a), for instance, the verb fik-a 'come' is intransitive:
a. fik-a 'come'
b. fik-is-a
'make come'
c. fik-is-w-a
'be made to come'

In (72b), fik-is-a 'make come' is made transitive by the causative suffix -is-, and, as a result, can be passivized as in (72c). Now note the possible reduplications of (72c) in (73a).
a. fik-i+fik-is-w-a
b. ${ }^{*}$ fik-w-a+fik-is-w-a
fik-a+fik-is-w-a 
As seen, the reduplicant consists of the root fik- plus either the [i] of the causative suffix -is- or the default FV $-a$. In (73b) we see that it is not possible to parse the passive $-w$ - in the reduplicant because th is would imply that fik- 'come' had become passivized in the first cycle-which is, of course, not the case, since the verb is intransitive. This effect is automatically obtained from the approach taken here: Rather than predicting the properties of the reduplicant by reference to the surface output of the corresponding base, the full range of facts is accounted for by attributing to the D-stemRED the full morphosyntactic structure of the base. This morphosyntactic structure is in turn spelled out in the normal way, subject to the cophonology of the reduplicant, e.g. the two-syllable constraint. Most interesting is the role played by this constraint in producing reduplications such as phek-w-a+phek-el$w-a$ in (71). While a superficial comparison of base and reduplicant suggests a violation ADJACENCY, it is the underlying structure in (71) combined with $[\sigma \sigma]$ that make the reduplicant phek-w-a+ possible. Because of the prosodic constraint, both -w- and -el-cannot be parsed. In addition, ${ }^{*}$ phek-w-e+ is not a possible reduplicant because the passive morph $-w$ - is not allowed to precede the applicative morph -el- (or its subpart, as -e would be in this case). The reduplicant phek-w-a+ is possible because it respects the hierarchical morphosyntactic structure in (71), and, crucially, because there is no requirement that the feature APPLICATIVE be spelled out in the reduplicant. If that option is taken, however, then the only possible grammatical output is phek-e+phek-el-w-a, which more closely resembles the surface order of the $-e l-w$ - sequence.

Examples of this sort can be produced with respect to other suffixes and other morphosyntactic situations. Ndebele thus provides strong evidence that the potential spell-outs of a reduplicant are governed by more than superficial resemblances with its base-and, once again, that as concerns the Bantu verb stem, morphology must proceed in a cyclic fashion (Hyman 1994, 1998).

\section{Conclusion}

At the outset of this study, we characterized the study of partial reduplication as having as its goal to construct a theory that insightfully captures the full range of considerations that speakers "care about" in determining how a reduplicant will relate to its base. What has the study of Bantu reduplication contributed toward this goal?

Certainly one very important contribution has been made in the work of Downing (1997a et seq.), in recognizing the important role that morphological structure plays in Bantu reduplication, which, therefore, is not solely a prosodic phenomenon. Mutaka and Hyman (1990) showed for Kinande the role that morphological considerations can play, as morpheme integrity can inhibit prosodic templatic effects in certain languages. Downing went further and showed the role that morphological constituent structure plays, noting effects of the derivational stem constituent on Bantu reduplication. In this paper we have taken this important insight a step further, finding that not only the D-stem as such but also its internal constituents-root, extension suffixes and filler suffixes-play a role in defining the variety of shapes of the Ndebele reduplicant. In making reference to D-stems and their constituents, the "canonical stem" shape to which Downing observed most reduplicants to adhere can actually be derived, rather than stipulated. This is an especially desirable outcome in Ndebele, where not all reduplicants are canonical stems in any case.

In fact, the comparative study of verb reduplication in Bantu shows that the phonological and morphological constraints on the reduplicant can be INDEPENDENTLY controlled to produce most of the possible combinations. In our introduction we cited Eulenberg (1971) as expressing the view that partial reduplication derives from total reduplication, i.e. by phonological and morphological paring down of the full base. Diachronic evidence for this position is quite clear as concerns the Bantu verb stem. Numerous Bantu languages require full verb stem reduplication, such as Luganda:
(74) a
lim-a
'cultivate'
lim-aa+lim-a 25

${ }^{25}$ Just in case the verb root is monomoraic, the FV of the reduplicant is lengthened. 


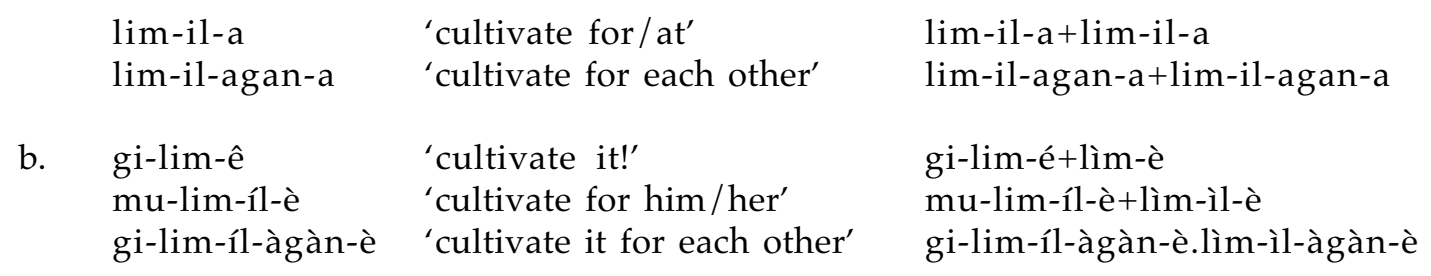

As seen, the copy is total, and the reduplicant thus includes any extensions that may be present, as well as the IFS, e.g. imperative/subjunctive - $e$ in (74b) — which also shows that the OM may not be parsed in the reduplicant. ${ }^{26}$

It is not difficult to explain why this original state of total reduplication should become modified over time: It is hardly necessary to repeat the whole verbal I-stem in order to convey the aspectual idea that the action is done a little here and there. It is therefore possible to economize and limit the reduplicant to a subpart of the base. This can be done either phonologically and/or morphologically, as we have seen. To begin with we can recognize the following two scales for these developments:

(75) Two scales for paring down the reduplicant

a . Phonological scale: full $>$ foot $>$ syllable $(>\text { mora }>\text { consonant? })^{27}$

b. Morphological scale: full $>$ derivational stem $>$ root

Evidence for such developments can of course be found within as well as outside of Bantu. The phonological scale consists of a gradual narrowing down of the reduplicant to fit a prosodic template, frequently a bisyllabic foot. The morphological scale consists of first restricting the reduplicant to derivational material, and ultimately to root material. As is known from Kikerewe (Odden 1996, Downing 1997c), there can be "intermediate" steps. In this language, a verb that has two or more extensions can be reduplicated fully, or can copy zero, one or more of these extensions. As seen in (76), the major constraint is that the D-stemRED must be spelled out from the left:

(76) Possible reduplicants of lim-il-an-a 'cultivate for each other' in Kikerewe (Odden 1996)
a. ku-lim-il-an-a+lim-il-an-a
b. ku-lim-il-a+lim-il-an-a
c. ku-lim-a+lim-il-an-a
d. *ku-lim-an-a+lim-il-an-a

'to cultivate for each other' + RED

(ku- = infinitive prefix; -il- =

applicative, -an- $=$ reciprocal)

Restricting ourselves to verb stem reduplication in Bantu, the specific choices speakers make can be listed as parameter settings, as in (77).

\footnotetext{
${ }^{26}$ Luganda thus provides evidence for the traditional view that the OM is outside the I-stem. We have concluded otherwise for Ndebele, since the OM may be reduplicated if the root is -C-, while the IFS may never be. An alternative that is worth pursuing is that reduplication is always the M-stem in Ndebele-and that the M-stem includes the I-stem. In this case the IFS may not be spelled out by a simple constraint saying that inflectional suffixal material must appear at the end of the R-stem (which now dominates the whole structure). Since we have already seen that OM will reduplicate only if the root is exhaustively parsed, there is no harm in requiring the M-stem to be duplicated as the morphosyntactic structure of the reduplicant. In Luganda, on the other hand, where the OM may never appear in the reduplicant, the latter is limited to the I-stem.

${ }^{27}$ The end stage of the phonological scale is noted by Niepokuj (1991:127) to have occurred in Trukese and Sahaptin, though we are not aware of any such cases involving Bantu verb stem reduplication.
} 
(77) Parameter settings for the Bantu reduplicant

a. Phonology:

(i) Size constraint:

(ii) Tone:

yes/no (if yes: 1 vs. 2 syllables)

yes/no

b. Morphology:
(i) IFS:
yes/no
(ii) OM:
yes/no
(iii) $\mathrm{FV}=-\mathrm{a}$ :
yes/no
(iv) $\operatorname{MAX}($ Root)
(Kukuyu vs. Ndebele)

Besides the possibility of a size constraint, another phonological condition can be that tone is not reduplicated. This appears to be the case in verb stem reduplication in all of the Eastern and Southern Bantu languages except Chichewa (Mtenje 1988, Kanerva 1989, Hyman \& Mtenje 1992, Myers \& Carleton 1996). In Chichewa there is both full I-stem reduplication as well as transfer of tone. The imperative forms illustrate in (78), where verb stem reduplication again marks a frequentative or distributive 'here and there' sense:
a. meny-a
thandiz-a
vundikir-a
fotokoz-er-a
'hit!'
'help!'
'cover!'
'explain to!
$\rightarrow \quad$ meny-a+meny-a
$\rightarrow \quad$ thandiz-a+thandiz-a
fotok
b. $\quad$ pez-á
namiz-á
thamang-ir-á
$\rightarrow$
vundikir-a+vundikir-a
$\rightarrow \quad$ fotokoz-er-a+fotokoz-er-a
khululukir-á
'find!'
'deceive!'
'run to!'
'pardon!'
$\rightarrow \quad$ pez-á+péz-á
$\rightarrow \quad$ namiz-á+namiz-á
$\rightarrow \quad$ thamang-ir-á+thamang-ir-á
$\rightarrow \quad$ khululukir-á+khululukir-á

In (78a) the verb roots of one to four syllables are toneless, while the corresponding verb roots in (78b) carry an underlying $\mathrm{H}$ tone. By a regular tonal process, a root $\mathrm{H}$ is realized on the $\mathrm{FV}$. The reduplicated forms in (78b) show that this $\mathrm{H}$ is realized on the FV of both the reduplicant and the base. As Hyman \& Mtenje (1999) demonstrate, Chichewa is unusual in that both the reduplicant and the base constitute prosodic words on their own-and, as a result, must both meet the bisyllabic minimum. Each has its own tone assignment, and the tone sandhi that occur across the reduplicant-base juncture are the same as apply across syntactic words, e.g. verb + noun object. ${ }^{28}$ We assume that full repetition of the verb stem as a separate prosodic word represents the original verb stem reduplication process in Proto-Bantu. While this means that tone will also be copied, in most other Bantu languages, the domain for tone is the Rstem: there can be only one root $\mathrm{H}$ tone, and any suffixal $\mathrm{H}$ tone is assigned only once to the whole reduplicant+base.

Concerning the morphological parameters, we have seen that languages variably reduplicate or fail to reduplicate the IFS. We believe that the latter case should be interpreted the same way as tone: The domain of the IFS is the R-stem. Since tonal suffixes are also inflectional, failure to transfer tone as well as the IFS result in the marking of inflection only once-and at the right edge of the entire verb form. This is, of course, in accordance with general Bantu verb structure.

Concerning the possibility of reduplicating the OM (and thereby raising the process to the level of the M-stem), we hypothesize that copying the OM is not original. Rather, verb reduplication was originally limited to the I-stem. Reduplication of the OM is thus a subsequent development motivated by two separate phonological conditions. The first, seen in Ndebele, occurs when the verb stem is

${ }^{28}$ This includes the $\mathrm{H}$ tone spreading rule that occurs in the environment $\mathrm{H \#} \mathrm{L}-\mathrm{H}$ and is responsible for the change of pez-á+pez-á to pez-á+pézá in (78b). 
monosyllabic and the OM is copied in order to fill out the bisyllabic foot condition on the reduplicant. As indicated in (79), this is one of three strategies that have been noted:

(79) Strategies invoked to fill out $[\sigma \sigma]$ condition on reduplicant

a. "move up" to M-stem and copy the OM, if there is one, e.g. Ndebele class $10 z i$ -

b. fill with "dummy" syllable, e.g. Ndebele $y i$ -

c. double reduplicate the monosyllabic stem, e.g. $s w-a-s w-a+s w-a$ 'grind here and there' in Kinande (Mutaka \& Hyman 1990)

As seen, Ndebele uses two of these strategies, allowing either the $\mathrm{OM}$ or the filler syllable yi- to appear in the reduplicant, when needed. Kinande, on the other hand, is one of several Bantu languages that double reduplicate monosyllabic verbs to fill out the bisyllabic template.

The second situation in which the OM sometimes becomes reduplicated is when it fuses with the root, i.e. when the $\mathrm{OM}$ is either a homorganic nasal, or a CV-prefix followed by V-initial root, as in Kihehe (Odden \& Odden 1985): 29

(80) OM reduplicates only when it fuses with the root
a. kú-fi-gul-a+gul-a
'to buy a bit of them (class 8)'
b. kú-mw-imb-il-a+mw-imb-il-a
'to sing a bit to him'
c. n-dím-il-e+n-dim-il-e
'cultivate a bit for me!'

The Kihehe example in (80a) shows that an OM does not reduplicate if it constitutes a syllable separate from the verb root. In (80b) we see the reduplication of CV- (here realized CG-) when the root is vowel-initial, and in (80c) we see that the nasal prefix, which prenasalizes the following consonant, is also reduplicated. The motivation in this case is that speakers seek to have the reduplicant and base begin with the same elements (cf. ANCHOR-L in note 14). Luganda does not do this, and so the reduplicant may begin differently from the base, when the latter is vowel-initial:
a. ku-er-a
[kwee.ra]
tú-er-a
[twéè.r-a]
'to sweep'
'we sweep'
'to sweep it'
ku-gí-er-a
[ku.gyéè.ra]
's/he will sweep'
(infinitive prefix ku-)
(1pl subject tú-)
(class 9 OM -gí-)
a-lí-er-a
[a.lyéè.ra]
[kwee.raa.ye.ra]
'to sweep here and there'
b. ku-er-aa+yer-a
[twéè.raa.ye.ra]
'we sweep here and there'
tú-er-aa+yer-a
[ku.gyéè.raa.ye.ra] 'to sweep it here and there'
ku-gí-er-aa+yer-a
[a.lyéè.raa.ye.ra]
's/he will sweep here and there'
c. n-jer-a
'I sweep'
$\rightarrow$
n-jer-a+yer-a

In (81a) we see the verb root -er- 'sweep' appearing after four different CV-prefixes. As seen in the syllabifications to the right, in each case the base -er- is vowel-initial and fuses with the preceding prefix. Unlike Kihehe, the corresponding reduplications in (81b) show that these prefixes are not doubled in reduplication. Instead, the reduplicant fuses with the prefix, while the base always begins with $[y] \cdot{ }^{30}$ As a result, the first syllable of the reduplicant is not identical to the first syllable of the base as it is in Kihehe.

${ }^{29}$ The limited data in Odden \& Odden (1985) are unusual in that prefixes other than the OM can also reduplicate when fused to the stem, e.g. the first person singular subject prefix N-.

${ }^{30}$ As shown by Hyman \& Katamba (1999), this [y] occurs whenever a vowel-initial root is not preceded by a CV- prefix. Compare, for example, yer-a 'sweep!', a-yer-a 's/he sweeps' etc. 
Turning now to the tendency for the reduplicant to end in -a, we note, as does Downing (1997b), that this is the most frequent verb ending in most Bantu languages. However, rather than seeing this as an indication of a special "canonical verb stem", we believe it is necessary to have a Bantu-specific constraint FV[-a], whose effects are, in fact, not restricted to verb reduplication-or even verbs-in Bantu. ${ }^{31}$ There is in fact considerable evidence that $-\mathrm{a}$ is the default stem-final vowel, whether its function is inflectional or derivational, and whether applying to nouns or verbs.

First, it is true, as Downing points out, that -a is used as an inflectional default FV in many Bantu languages. In Pende, for example, the recent past tense is marked by the IFS $-i$ if immediately preceded by a CV-, CVC- or CGVC- verb root, as in $(82 \mathrm{a}, \mathrm{b}, \mathrm{c})$ respectively: ${ }^{32}$

\begin{tabular}{|c|c|c|c|}
\hline $\begin{array}{l}\text { tw-a-mb-í } \\
\text { tw-a-y-í }\end{array}$ & $\begin{array}{l}\text { 'we put' } \\
\text { 'we went' }\end{array}$ & $\begin{array}{l}- \text { mba- } \\
- \text { yi- }\end{array}$ & $\begin{array}{l}\text { 'put' } \\
\text { 'go' }\end{array}$ \\
\hline $\begin{array}{l}\text { tw-a-som-í } \\
\text { tw-a-meng-í }\end{array}$ & $\begin{array}{l}\text { 'we loaded (a gun)' } \\
\text { 'we detested' }\end{array}$ & $\begin{array}{l}\text {-som- } \\
\text {-meng- }\end{array}$ & $\begin{array}{l}\text { 'load (a gun)' } \\
\text { 'detest' }\end{array}$ \\
\hline $\begin{array}{l}\text { tw-a-kwec-í } \\
\text { tw-a-mwang-í }\end{array}$ & $\begin{array}{l}\text { 'we tied' } \\
\text { ‘we scattered' }\end{array}$ & $\begin{array}{l}\text {-kuet- } \\
\text {-muang- }\end{array}$ & $\begin{array}{l}\text { 'tie' } \\
\text { 'scatter' }\end{array}$ \\
\hline $\begin{array}{l}\text { tw-a-vumbíg-á } \\
\text { tw-a-digím-á }\end{array}$ & $\begin{array}{l}\text { 'we buried' } \\
\text { 'we were afraid' }\end{array}$ & $\begin{array}{l}\text {-vumbig- } \\
\text {-digim- }\end{array}$ & $\begin{array}{l}\text { 'bury' } \\
\text { 'be afraid' }\end{array}$ \\
\hline $\begin{array}{l}\text { tw-a-som-él-á } \\
\text { tw-a-som-és-á }\end{array}$ & $\begin{array}{l}\text { 'we loaded for/at' } \\
\text { 'we made load' }\end{array}$ & $\begin{array}{l}\text {-som-el- } \\
\text {-som-es- }\end{array}$ & $\begin{array}{l}\text { 'load + applicative' } \\
\text { 'load + causative' }\end{array}$ \\
\hline $\begin{array}{l}\text { tw-a-mb-él-á } \\
\text { tw-a-mb-és-á }\end{array}$ & $\begin{array}{l}\text { 'we put for / at' } \\
\text { 'we made put' }\end{array}$ & $\begin{array}{l}\text {-mba-el- } \\
\text {-mba-es- }\end{array}$ & $\begin{array}{l}\text { 'put }+ \text { applicative' } \\
\text { 'put }+ \text { causative' }\end{array}$ \\
\hline
\end{tabular}

In (82d) we see that when the stem consists of two full syllables (or more), the IFS must be -á. In these examples the root is morphologically unanalyzeable. In (82e), where a -CVC-root is followed by a -VC- extension, the same $-a$ is required. Finally, in (82f), where the first stem syllable consists of a CVroot which has fused with the V of a -VC- extension, we also must get the default FV -á rather than $-i$. The generalization is, therefore, that $-i$ can occur only within the second syllable of a verb stem whose base is morphologically simplex. Otherwise the recent past tense reverts to default $-a$.

While the Pende case in (82) involves inflection, other languages have default $-a$ in derivational processes-and on nouns. In Luganda, for instance (Ashton et al 1954), as seen in (83a), the -i suffix is used to derive agentive nouns from verbs: ${ }^{33}$
a. mu-lim-i
mu-gass-i
mu-tonz-i
'farmer'
'mediator'
'creator'
mu-vúz-ì
'driver'
b. mu-sóm-ès-a 'teacher'
mu-záàl-is-a 'midwife'

$\begin{array}{ll}\text {-lim- } & \text { 'cultivate' } \\ \text {-gatt- } & \text { 'unite, unify, put together' } \\ \text {-tond- } & \text { 'create' } \\ \text {-vúg- } & \text { 'steer, drive' } \\ \text {-sóm- } & \text { 'read, study' } \\ \text {-sóm-es-- } & \text { 'teach' } \\ \text {-záal- } & \text { 'give birth' }\end{array}$

${ }^{31}$ In Basaa, for instance, nouns are diminutivized by a partial reduplicating the stem and shifting it to class 19/13 (prefixes hi-/di-). As seen in the following examples provided by Deborah Schmidt, the full form typically ends in -a: mim 'body' $\rightarrow$ hi-mi+mím-á, bel 'thigh' $\rightarrow$ hi-6e+6él-á, loy 'country' $\rightarrow$ hi-lo+lón-á.

${ }^{32}$ Study of gi-Pende was made possibly by two visits to Berkeley of Mwatha Ngalasso, who also points out that the final $-\mathrm{i}$ of the recent past optionally assimilates to the preceding vowel. Thus, the two forms in (80b) may also be realized tw-a-som-ó and tw-a-meng-é.

${ }^{33}$ Non-labial oral consonants are also mutated to $[\mathrm{s}]$ or $[\mathrm{z}]$ before the historically tense vowel *-. 


\begin{tabular}{|c|c|c|c|}
\hline mu-zis-â & $\begin{array}{l}\text { 'one who lets garden } \\
\text { grow wild' }\end{array}$ & $\begin{array}{l}\text {-zik- } \\
\text {-zis-- }\end{array}$ & $\begin{array}{l}\text { 'grow wild' } \\
\text { 'let (garden) grow wild' }\end{array}$ \\
\hline mu-fúús-à & 'magician' & $\begin{array}{l}\text {-fuuk- } \\
\text {-fuus-- }\end{array}$ & $\begin{array}{l}\text { 'become, change (intr.)' } \\
\text { 'cause to become, change (tr.)' }\end{array}$ \\
\hline mu-kúz-à & 'guardian of a minor & $\begin{array}{l}\text {-kul- } \\
\text {-kuz-- }\end{array}$ & $\begin{array}{l}\text { 'grow' } \\
\text { 'cause to grow' }\end{array}$ \\
\hline mu-júl-ìr-w-à & 'witness' & $\begin{array}{l}\text {-júl-ir- } \\
\text {-júl-ir-w- }\end{array}$ & $\begin{array}{l}\text { 'call to witness' } \\
\text { 'be called as a witness' }\end{array}$ \\
\hline mu-lek-w-â & 'orphan' & $\begin{array}{l}\text {-lek- } \\
\text {-lek-w- }\end{array}$ & $\begin{array}{l}\text { 'leave, let' } \\
\text { 'be left, abandoned' }\end{array}$ \\
\hline mu-liráàn-w-à & 'neighbor' & $\begin{array}{l}\text {-liraan- } \\
\text {-liraan-w- }\end{array}$ & $\begin{array}{l}\text { 'adjoin' } \\
\text { 'be adjoined' }\end{array}$ \\
\hline mu-súút-w-à & 'well-beloved, darling' & $\begin{array}{l}\text {-suut- } \\
\text {-suut-w- }\end{array}$ & $\begin{array}{l}\text { 'praise' } \\
\text { ‘be praised' }\end{array}$ \\
\hline
\end{tabular}

However, as seen in $(83 b, c)$, when the agentive noun is derived from a causative verb ending in $[\mathrm{s}]$ or $[\mathrm{z}]$, -a must be used instead. In (83b) the causative suffix is underlingly -is-- (harmonizing to -es--), while in in (83c), the short causative extension -- is used alone. In both cases, the tense "' glides to [y] and is "absorbed" into the preceding $[\mathrm{s}]$ or $[\mathrm{z}] .{ }^{34}$

It is clear from such evidence that the use of the FV $-a$ is logically independent of reduplication. In this study we also suggest that it is also logically independent of the bisyllabic CVC-a shape which Downing has referred to as a the "minimal canonical stem". To see this, consider the following forms from Lengola (Stappers 1971:268), where verb stem reduplication marks the habitual:

\begin{tabular}{|c|c|c|c|}
\hline a. & $\begin{array}{l}\text { i-kul-a } \\
\text { i-bon-a } \\
\text { i-túm-a } \\
\text { i-límb-a }\end{array}$ & $\begin{array}{l}\text { 'acheter' } \\
\text { 'regarder' } \\
\text { 'envoyer' } \\
\text { 'chanter' }\end{array}$ & $\begin{array}{l}\text { i-kul-a+kul-a } \\
\text { i-bon-a+bon-a } \\
\text { i-túm-a+tum-a } \\
\text { i-límb-a+limb-a }\end{array}$ \\
\hline b. & $\begin{array}{l}\text { i-kpet-a } \\
\text { i-ki-a } \\
\text { i-gbok-a }\end{array}$ & $\begin{array}{l}\text { 'couper' } \\
\text { 'faire' } \\
\text { 'trouver' }\end{array}$ & $\begin{array}{l}\text { i-kp-a+kpet-a } \\
\text { i-k-a+ki-a } \\
\text { i-gb-a+gbok-a }\end{array}$ \\
\hline c. & $\begin{array}{l}\text { i-6í-a } \\
\text { i- } \beta \hat{1}-a \\
\text { i- } \phi a ́ m-a\end{array}$ & $\begin{array}{l}\text { 'manger' } \\
\text { 'parler' } \\
\text { 'crier' }\end{array}$ & $\begin{array}{l}\text { i- } 6-\hat{a}+6 i-a \\
i-\beta-\hat{a}+\beta i-a \\
i-\phi-\hat{a}+\phi a m-a\end{array}$ \\
\hline
\end{tabular}

In (84a) we observe full root+FV reduplication (preceded by the infinitive prefix $i$-). However, Stappers also indicates that verbs such as those in $(84 b, c)$ form their habitual by means of a [Ca] reduplicant. The most straightforward analysis is that in these forms D-stemRED is limited to one syllable (vs. the more usual two) and must end in $-a .{ }^{35}$

\footnotetext{
${ }^{34}$ It is conceivable that this use of this -a, which appears to carry underlying high tone, was originally motivated by a desire not to have one *followed by another. Even if one wished to maintain this as a construction-specific constraint, what is important is that -a is used as the default, not some other vowel.

${ }^{35}$ The falling tone on the reduplicant in $(84 \mathrm{c})$, found when the verb root is high tone, suggests two tonebearing units, as if there has been a truncation. Unfortunately Stappers does not give many examples or discuss this construction in any detail.
} 
A similar conclusion is drawn from gerundive reduplication in Lomongo (Hulstaert 1965):

Verb

$\begin{array}{ll}\text {-lík- } & \text { 'lancer' } \\ \text {-léng- } & \text { 'duper' } \\ \text {-kéng- } & \text { 'être vivant' } \\ \text {-kúk- } & \text { 'couvrir' } \\ \text {-tól- } & \text { 'insulter' } \\ \text {-tók- } & \text { 'piler' }\end{array}$

Gerundive

\section{Bombwanja dialect Coquilhatville \& Northern dialects}

$$
\begin{aligned}
& \text { n-dí+lík-a } \\
& \text { n-dé+léng-a } \\
& \text { n-ké+kéng-a } \\
& \text { n-kú+kúk-a } \\
& \text { n-tó+tól-a } \\
& \text { n-tó+tók-a }
\end{aligned}
$$

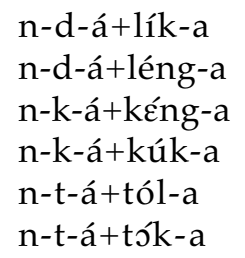

In this case of verb reduplication, the reduplicant again consists of a single CV syllable. In Bombwanja dialect, the CV corresponds to the initial CV of the base. In Coquilhatville and Northern dialects of Lomongo, however, it has the shape [Ca]. As in Lengola, the fixed vocalism is presumably a reflection of the FV $-a$, hence the reduplicant can be analyzed as C-a+. If we were to extend Downing's analysis of the Kinande "minimal canonical D-stem" CVC-a, we would have to say that in Lengola and Lomongo

\begin{tabular}{|c|c|c|c|c|}
\hline (86) a. & $\begin{array}{l}\text { kor-a } \\
\text { cin-a }\end{array}$ & $\begin{array}{l}\text { 'grow' } \\
\text { 'burn' }\end{array}$ & $\begin{array}{l}\rightarrow \\
\rightarrow\end{array}$ & $\begin{array}{l}\text { kor-a+kor-a } \\
\text { cin- } a+c i n-a\end{array}$ \\
\hline b. & $\begin{array}{l}\text { koor-a } \\
\text { ßuut-a }\end{array}$ & $\begin{array}{l}\text { 'pull out' } \\
\text { 'depose' }\end{array}$ & $\begin{array}{l}\rightarrow \\
\rightarrow\end{array}$ & $\begin{array}{l}\text { koor-a+koor-a } \\
\text { ßuut-a+ßuut-a }\end{array}$ \\
\hline c. & $\begin{array}{l}\text { ßocor-a } \\
\text { hoorer-a }\end{array}$ & $\begin{array}{l}\text { 'be indented' } \\
\text { 'be quiet' }\end{array}$ & $\rightarrow$ & $\begin{array}{l}\text { 乃oc- } a+\beta \text { ocor-a } \\
\text { həor-a+hoorer-a }\end{array}$ \\
\hline d. & $\begin{array}{l}\text { ciferer-a } \\
\text { hwererek-a }\end{array}$ & $\begin{array}{l}\text { 'encircle' } \\
\text { 'tilt' }\end{array}$ & $\rightarrow$ & $\begin{array}{l}\text { cif-a+ciyerer-a } \\
\text { hwer-a+hwererek-a }\end{array}$ \\
\hline
\end{tabular}
the minimal canonical D-stem is C-a+. However, we know of no evidence for this. Rather, in this construction we would simply say that RED $=\sigma$ and the Bantu-specific constraint FV[-a] is ranked high.

Finally, note that even in languages where there is a bisyllabic minimum in effect, CVC-a can be a possible reduplicant without there having to be a corresponding CVC- root. The example comes from Kikuyu (Peng 1991; see also Downing (1999)):

When the base is CVC-a or CVVC-a, as in $(86 a, b)$, reduplication appears to be total. ${ }^{36}$ The longer stems in $(86 c, d)$ indicate, however, that only the first $C V(V) C$ - may appear in the reduplicant, and that the $\mathrm{FV}-a$ is required. In order to account for this, Peng refers to the initial $\mathrm{CV}(\mathrm{V}) \mathrm{C}$ - of verbs as a prosodic minimal root $\left(R_{\min }\right)$ which has the shape $[\sigma . C]$. In our framework, the FV[-a] simply outranks $\operatorname{MAX}($ Root).

What these data from Lengola, Lomongo and Kikuyu clearly show is that each of the properties of reduplicants can be independently manipulated and reranked in terms of the appropriate constraints. Thus, although Max(Root) is very important cross-linguistically, it can be outranked by RED $\sigma \sigma]$ in Ndebele, by RED $[\sigma]$ in Lengola and Lomongo, or by FV[-a] in Kikuyu. In fact, Max(Root) can appears to be even more seriously violated in at least some realizations in Bukusu. In order to appreciate these, however, we need to seek explanations for two crucial—and, as we shall suggest—related questions:

(87) Two crucial questions

a. Why should there be a tendency to realize as much of the root as possible in Bantu verb stem reduplication? (I.e. why is MAX(Root) so highly ranked?)

36Peng cites forms without tones and without FV. We have added -a to all verb bases to make them more comparable to those seen in Ndebele and elsewhere in this study. 
b. Why is Bantu verb stem reduplication prefixal?

The most immediate answer that linguists will probably advance to the first question is that roots-an open morphological class-are universally more salient than grammatical affixes. This response was so automatic, originally, on our part, that we did not even raise the question. However, a moment's reflection will reveal that this answer is insufficient. The fact that the root plays such an important role in Bantu verb stem reduplication is clearly attributable to a second fact, namely that a Bantu verb stem reduplication is prefixal. As originally observed by Marantz (1982), prefixal reduplication tends to left-anchored, while suffixal reduplication tends to be right-anchored. Schematically, the "unmarked" mappings (in Marantz's framework) or Base-Reduplicant correspondences (McCarthy \& Prince 1995) are as in (88a).

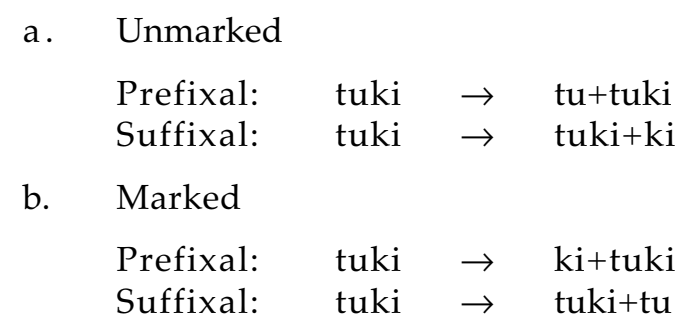

The marked mappings/correspondences are shown in (87b). Niepokuj (1991) speculates that the more widespread (unmarked) situation in (87a) has a functional explanation: In these outputs the copied sequence in the reduplicant appears adjacent to the same sequence in the base. As a result, the reduplicative process is more transparent, i.e. not requiring a long-distance identification as in (88b). It is therefore to be expected that there will be greater faithfulness to the root in prefixal reduplication than there will be to suffixes.

In order to show that this is the correct interpretation, consider what Bantu verb stem reduplication would look like if it were suffixal. Let us take the same forms we considered from Ndebele in (3) and assume that the suffixed reduplicant is subject to $\operatorname{Red}(\sigma \sigma)$. Possible outputs might be those indicated in (89).

\section{Plain verb stem}

a. lim-el-a

lim-is-a

b. lim-el-a

lim-is-a

\section{Verb stem with suffixed reduplicant}

$\begin{array}{lll}\text { lim-el-a+lim-e } & \text { 'cultivate for/at' } & \text { (applicative -el-) } \\ \text { lim-el-a+lim-a } & & \\ \text { lim-is-a+lim-i } & \text { 'make cultivate' } & \text { (causative -is-) } \\ \text { lim-is-a+lim-a } & & \\ \text { lim-el-a+m-el-a } & \text { 'cultivate for } / \text { at' }^{\prime} & \\ \text { lim-is-a+m-is-a } & \text { 'make cultivate' } & \end{array}$

In the mirror image realizations of Ndebele in (89a), we have considered two variants for each reduplication: the first copies the first two syllables of the base, while the second uses the FV $-a$. However, note that these realizations represent the "marked" base-reduplicant correspondence in (88b). They are, in fact, unattested in Bantu. The unmarked BR correspondence with right-anchoring is given in (89b). Here we have preserved the suffixes at the expense of (part of) the root -lim-. The realizations in (89b) violate $\operatorname{MAX}($ Root) in a way that (89a) does not, but can we say that they are any the less "natural" or expected? 
While we have not (yet?) found exact outputs as in (89b) in any Bantu language, we have noted some variants in Bukusu that are highly suggestive. ${ }^{37}$ Thus, consider the reduplications in (90).
a. lim-a
'cultivate'
'cut'
$\rightarrow \quad$ lim-a+lim-a
b. lim-il-a
'cultivate for/at'
$\rightarrow \quad$ rém-a+rem-a
c. kacul-a
'cut for / at'
$\rightarrow \quad$ lim-a+lim-il-a
$\rightarrow$ rém-a+rem-er-a
$\rightarrow$ kacul-a+cul-a
mulix-a
'chat, talk'
'flash'
$\rightarrow$ mulix-a+lix-a

In (90a) we observe total reduplication of the bisyllabic verb stems. In (90b), where the applicative suffix has been added, the tendency for a prefixed reduplicant is also in evidence. Consider, however, the forms in (90c), where the stem contains an unanalyzeable CVCVC- verb base. While some such verbs reduplicate fully, these reduplicate by means of a truncated "second part", i.e. by apparent suffixation. ${ }^{38}$ The generealization is that the speaker choose to isolate the root at the left and the suffixes at the right of the TOTAL form. Why should this be?

We suggest that the answer is the same one to our second question, given in (87b): Why should Bantu verb stem reduplication be prefixal? The reason is that the verb stem is a suffixal constituent, as we have seen. Speakers are therefore accustomed to both derivational and inflectional grammatical marking at the right edge of the stem. If reduplication were to proceed as in (89a), this general organizing principle would be violated. The resolution is thus as in (90b): The root appears at the left of the structure, where it is expected, and the suffixes appear at the right, where they too are expected. The resolution in (90c) is thus ingenious in that the second part of the R-stem includes all of the suffixal material-and only a minimum of root material. The fact that any of the root occurs in the second part at all is presumably due to the otherwise exceptionless property that affixes cannot occur without a root. Since, as we indicate in note 37, this is but one of the reduplicative strategies employed by our consultant, it would be much more interesting if some Bantu language had only this pattern.

To summarize this last result, we suggest that $\operatorname{MAX}($ Root) is driven by the suffixal nature of the Bantu verb stem. We therefore make the more general markedness claims in (91) concerning the affix orientation of the reduplicant cross-linguistically:

\section{Unmarked direction $=$ "opposite edge affixation" in reduplication}

a. The reduplicant will tend to be prefixed when the base has a suffixing structure

b. The reduplicant will tend to be suffixed when the base has a prefixing structure

We have already seen the evidence for (91a) in Bantu verb stem reduplication. One of the many languages that can be cited in this regard is Kinande. With respect to (91b) it is interesting to note that noun reduplication is, however, suffixal in Kinande. As Mutaka \& Hyman (1990) demonstrate, noun reduplication is a word-level process:

\section{Kinande noun reduplication}

${ }^{37}$ These forms were collected by Julia Hill in an undergraduate field methods course at UC Berkeley in Fall 1997. The consultant was Wanjala Khisa, who showed a great deal of variation (and with whom Laura Downing is pursuing a more detailed study). What is important to us at this point is that such forms were volunteered and seem to be acceptable, at least as options in some cases.

${ }^{38}$ We use the designations "first part" and "second part" instead of reduplicant and base, since it is not evidence which is which in these forms. This problem, anticipated in Niepokuy (1991), is further explored in Inkelas \& Zoll (1999). 


\begin{tabular}{|c|c|c|}
\hline $\begin{array}{l}\text { ku-gulu } \\
\text { mu-góngò } \\
\text { kú-boko }\end{array}$ & $\begin{array}{l}\text { 'leg' } \\
\text { 'back' } \\
\text { 'arm' }\end{array}$ & $\begin{array}{l}\text { ku-gulu.gulu } \\
\text { mu-góngo.góngò } \\
\text { kú-bokó.boko }\end{array}$ \\
\hline $\begin{array}{l}\text { o.mú-twe } \\
\text { bi-la } \\
\text { ká-tì }\end{array}$ & $\begin{array}{l}\text { 'head' } \\
\text { 'intestines' } \\
\text { 'stick' }\end{array}$ & $\begin{array}{l}\text { mú-twé.mú-twe } \\
\text { bi-la.bi-la } \\
\text { ká-tí.ká-tì }\end{array}$ \\
\hline
\end{tabular}

The direction of affixation is not evident in (92a), where we might think that it is the stem that has been (totally) reduplicated. However, the nouns in (92b) provide the answer. Here, the noun class prefix is also reduplicated to fill out the bisyllabic prefixal template. Mutaka \& Hyman's analysis is that the prefix+stem is reduplicated as a suffix, and the noun prefix is copied in (91b) because the stem is monosyllabic. In our view, suffixal reduplication is possible in noun reduplication because nouns are not characterized by the potential sequencing of a highly developed system of suffixes. Instead, they are most notably marked by noun class prefixes. As such, they are good candidates for suffixal reduplication, as per (91b).

\section{Conclusion}

In this study we have had several goals. A first goal has been to document in some detail the nature of verb stem reduplication in Ndebele. A second goal has been to contribute to discovering the full class of reduplicative "parameters" that can be set by means of different constraint rankings. In so doing, a third goal has thus been to contribute to the Optimality Theory literature in providing yet another example of language-internal variation which can be attributed to free constraint ranking, by illustrating the need for enforcement of constraints on subtrees (cyclicity) and by providing a morphological reanalysis of apparent backcopying in reduplication.

\section{References}

Alsina, Alex. 1999. Where's the mirror principle? The Linguistic Review 16.1-42.

Anttila, Arto. 1994. Deriving variation from grammar: a study of Finnish genitives. Ms.

Ashton, E.O. et al. 1954. A Luganda grammar. London: Longmans, Green \& Co.

Baker, Mark. 1985. The mirror principle and morphosyntactic explanation. Linguistic Inquiry 16.373416.

Bastin, Yvonne. 1983. La finale -IDE et l'imbrication en bantou. Tervuren: Annales du Musée Royale de l'Afrique Centrale. Série IN-8, Sciences Humaines. N. 114.

Chen, Su-I and Gloria Malambe. 1998. Palatalization in SiSwati: an optimality theoretic approach. In Ian Maddieson \& Thomas J. Hinnebusch (eds), Language history and linguistic description in Africa, 137-146. Trenton, N.J.: Africa World Press, Inc.

Downing, Laura J. 1997a. Correspondence effects in Siswati reduplication. Studies in the Linguistic Sciences 25.81-95.

Downing, Laura. 1997b. Morphological correspondence in Kinande reduplication. Proceedings of Berkeley Linguistic Society 23.

Downing, Laura. 1997c. Morphological correspondence constraints on Kikerewe reduplication. Proceedings ofWCCFL 16.

Downing, Laura. 1999. Morphological constraints on reduplication. Ms. University of California, Berkeley.

Downing, Laura. In press. Prosodic stem - prosodic word in Bantu. Proceedings of Berlin Conference on the Phonological Word.

Eulenberg, John Bryson. 1971. Conjunction reduction and reduplication in African languages. In Chin-Wu Kim and Herbert Stahlke (eds), Papers in African linguistics, 71-80. Edmonton: Linguistic Research, Inc.

Futagi, Yoko. 1997. Root-reduplicant faithfulness. Proceedings of WCCFL 16. 
Grégoire , Claire. 1979. Les voyelles finales alternantes dans la conjugaison affirmative dans les langues bantoues centrales. Journal of African Languages and Linguistics 1.141-172.

Guthrie, Malcolm. 1962. On the status of radical extensions in Bantu languages. Journal of African Languages 1.202-220.

Hulstaert, G. 1965. Grammaire du Lçmçngç, Ile Partie, Morphologie. Tervuren: Musée Royal de l'Afrique Centrale.

Hyman, Larry M. 1994a. "Conceptual issues in the comparative study of the Bantu verb stem". Salikoko S. Mufwene \& Lioba Moshi (eds), Topics in African Linguistics, 3-34. Amsterdam: Benjamins.

Hyman, Larry M. 1994b. Cyclic phonology and morphology in Cibemba. In J. Cole and Charles Kisseberth (eds.), Perspectives in Phonology, 81-112. Stanford: C.S.L.I.

Hyman, Larry M. 1995 Minimality and the prosodic morphology of Cibemba imbrication. Journal of African Languages and Linguistics 16.3-39.

Hyman, Larry M. 1998. Cyclicity and non-correspondence in the Bantu verb stem. Paper presented at the Annual Meeting of the Linguistic Society of America, New York, January 9, 1998.

Hyman, Larry M. \& Francis X. Katamba. 1999. "The syllable in Luganda phonology and morphology". In Harry van der Hulst \& Nancy A. Ritter (eds), The syllable: views and facts.m, 349-416. Berlin: Mouton de Gruyter.

Hyman, Larry M. \& Sam Mchombo. 1992. Morphotactic Constraints in the Chichewa Verb Stem". Berkeley Linguistic Society 18.350-364.

Hyman, Larry M. \& Al Mtenje. 1999. Prosodic morphology and tone: the case of Chichewa. In René Kager, Harry van der Hulst, and Wim Zonneveld, eds., The prosody-morphology interface, 90-133. Cambridge: Cambridge University Press.

Inkelas, Sharon \& Cheryl Zoll. 1999. Reduplication as double stem selection. Presented at Phonology 2000 Symposium, Harvard University and MIT.

Itô, Junko and Armin Mester. 1997. Correspondence and compositionality: the Ga-gyo variation in Japanese phonology. In Iggy Roca, ed., Derivations and constraints in phonology. Oxford: Clarendon Press. 419-62.

Ito, Junko, Armin Mester and Jaye Padgett. 1995. Licensing and underspecification in Optimality Theory. Linguistic Inquiry 26:571-614.

Kanerva, Jonni. 1989. Focus and phrasing in Chcihewa phonology. Ph.D. Dissertation, Stanford University.

Kiparsky, Paul. 1986. The phonology of reduplication. Ms. Stanford University.

Kiparsky, Paul. 1997. Handout from LSA Summer Institute, Cornell University.

Marantz, Alec. 1982. Re reduplication. Linguistic Inquiry 13.435-482.

McCarthy, John \& Alan Prince. 1986. Prosodic morphology. Ms. U. Massachusetts, Amherst \& Brandeis University.

McCarthy, John \& Alan Prince. 1993. Generalized alignment. In Geert Booij and Jaap van Marle, eds., Yearbook of Morphology 1993. Dordrecht: Kluwer. 79-153.

McCarthy, John \& Alan Prince. 1995. Faithfulness and reduplicative identity. In J. Beckman, S. Urbanczyk \& L. Walsh (eds), Papers in optimality theory, 249-384. Amherst: GLSA.

Meeussen, A.E. 1967. Bantu grammatical reconstructions. Africana Linguistica 3.81-121. Annales du Musée Royale de l'Afrique Centrale. Série IN-8, Sciences Humaines. N. 121. Tervuren.

Mtenje, Al. 1988. On tone and transfer in Chichewa reduplication. Linguistics 26.125-155.

Mutaka, Ngessimo and Larry M. Hyman. 1990. Syllables and morpheme integrity in Kinande reduplication. Phonology 7.73-119.

Myers, Scott. 1987. Tone and the structure of words in Shona. Ph.D. dissertation, University of Massachusetts, Amherst.

Myers, Scott \& Troi Carleton. 1996. Tonal transfer in Chichewa. Phonology 13.39-72.

Niepokuj, Mary Katherine. 1991. The historical development of rduplication, with special reference to Indo-European. Ph.D. dissertation, University of California. Berkeley.

Odden, David. 1996. Patterns of reduplication in Kikerewe. In David Dowty et al (eds), Papers in phonology, 111-148. Working Papers in Linguistics No. 48. Ohio State University.

Odden, David and Mary Odden. 1985. Ordered reduplication in Kihehe. Linguistic Inquiry 16.497-503.

Orgun, C. Orhan. 1996. Sign Based Morphology and Phonology. PhD dissertation, UC Berkeley. 
Pelling, R. J. N. 1971. A Practical Ndebele Dictionary. Harare: Longman Zimbabwe (Pvt.) Limited.

Peng, Long. 1991. Root and foot in Kikuyu reduplication. Ms. University of Arizona.

Prince, Alan \& Paul Smolensky. 1993. Optimality theory: constraint interaction in generative grammar. Ms. Rutgers University \& Univeristy of Colorado.

Schadeberg, Thilo C. 1982. Les suffixes verbaux séparatifs en bantou. Sprache und Geschichte in Afrika 4.55-66.

Schlindwein, Deborah. 1986. On the "invisibility" of the first person singular object marker in Kirimi. Paper presented at the 17th Annual Conference on African Linguistics.

Sibanda, Galen. 1996. First passive paper.

Sibanda, Galen. 1999. Palatalization of labials in the Ndebele passive. Ms. University of California, Berkeley.

Sibanda, Galen. 1999b. Suffix ordering in Ndebele. Ms. University of California, Berkeley.

Stappers, Leo. 1971. Esquisse de la langue lengola. Africana Linguistica 5.257-307. Tervuren: Musée Royal de l'Afrique Centrale.

Steriade, Donca. 1988. Reduplication and syllable transfer in Sanskrit and elsewhere. Phonology 5.73155.

Steriade, Donca. 1997. Lexical conservatism and its analysis. Ms. U.C.L.A.

Urbanczyk, Suzanne. 1996. Patterns of Reduplication in Lushootseed. PhD dissertation, University of Massachusetts, Amherst.

Zoll, Cheryl. 1996. Parsing below the segment in a constraint based framework. Ph.D. dissertation, University of California, Berkeley. 